\title{
The Role of Bitcoin in Well Diversified Portfolios: A Comparative Global Study
}

\author{
Anton Kajtazi \\ Hanasoft Limited, London, UK \\ kajtazi@gmail.com \\ Andrea Moro \\ Cranfield University - School of Management, Cranfield, UK \\ andrea.moro@cranfield.ac.uk \\ (corresponding author)
}

\begin{abstract}
This research explores the effects of adding bitcoin to an optimal portfolio (naïve, long-only, semi-constrained with and without bitcoin shorting) by relying on the mean-CVaR approach. We explore bitcoin's role in portfolios of U.S., European and Chinese assets. We back-test to compare the performance of portfolios with and without bitcoin for each scenario. The results show that by adding bitcoin, the portfolio performance improves; but this is due more to the increase in returns than in the reduction of volatility. In addition, the improvement is linked to bitcoin's performance in 2013. We conclude that bitcoin may have a role in portfolio diversification even though our analysis confirms bitcoin speculative characteristics.
\end{abstract}

Keywords: Bitcoin, Cryptocurrencies, Portfolio Diversification, Portfolio Strategies

JEL classification: G11

Acknowledgement: we would like to thank attendees of the "Cryptocurrency Research Conference 2018” (24 May 2018) in Cambridge for their helpful feedback. We also want to thank the editor Professors Lucey as well as two anonymous reviewers. Their feedback allowed us to improve the analysis, develop it further and clarify some aspects of our research. 


\title{
The Role of Bitcoin in Well Diversified Portfolios: A Comparative Global Study
}

\author{
Raj: Wait what's Bitcoin?
}

Sheldon: "It's a new online currency that's been developed. It's just actual money except you can't see it, hold it or spend it on anything"

From: "The Bitcoin Entanglement" - Big Bang Theory, Season 11, Episode 09

\section{Introduction}

The Bardi Family used to be very powerful and rich in the fourteenth century. Their activities covered trading as well as banking (they ran one of the largest banks of the late middle age) and, together with the Peruzzi family, were among those who financed King Edward's III war efforts against France. When in 1345 England went bankrupt and was unable to repay them, they were forced out of business. In that very same year, three members of the Bardi family (namely Rubecchio, his uncle Aghinolfo and his cousin Sozzo), having lost almost their entire wealth decided to change their core activities: from bankers to forgers. The suspicious smoke and hammering sounds that could be easily heard when walking around their property, immediately attracted the attention of the local authorities. Due to their lack of expertise as forgers, they were caught at the very beginning of their new endeavour and on $15^{\text {th }}$ October 1345 the local authority started the proceedings against them (Cipolla, 1994). Interestingly enough, the major driver for their very clumsy attempt as forgers was the lack of liquidity and the re-valuation of silver and gold that characterised the years between 1333 and 1348 when the explosion of the Black Death completely reshaped the social and economic fabric around Europe.

Nowadays the link between metal and value of the currency (Metallism) is no longer relevant anymore and even if forging is an illegal activity that has its followers, the maladroit game attempted by the Bardi would not be possible nor effective since the vast majority currencies no longer come 
into existence by being printed. Institutions (i.e. the central banks and commercial banks) can expand money and debase it via quantitative easing and lending activity. The result is that the majority of dollars, euros or pounds are created by private banks when they make loans (de Soto, 1995).

In fact, the scepticism about the role of any central authority over the political and economic lives of individuals raises concern about traditional fiat currencies. Nakamoto (2008), the mysterious bitcoin founder, argues that fiat currencies are not a proper medium of exchange because of high transaction costs and the exclusion of a large part of the world population from the banking system. He also argues that fiat currencies do not function well as stores of value, due to the presence of excess inflation. Thus, he proposes Bitcoin as a new tool ${ }^{1}$ independent from any central authority, it is able to addresses these issues by making its supply pre-determined, constant, decreasing, and ultimately finite and thus deflationary. In addition, it aims to be an excellent store or value in the long run (Nakamoto, 2008). Interestingly, the last point raises a key question: if bitcoin is an excellent store of value, should it be included in a portfolio of assets?

Truthfully, ever since the seminal work by Markowitz $(1952,1976)$, finance stresses the importance of portfolio diversification and a lot of analysis explores the optimal mix of assets that allows for the maximisation of the return by minimising the risk (i.e. the volatility). Historically the focus was on shares (e.g. Treynor and Black 1973), bonds (e.g. Barnes and Burnie 1990), and derivatives (e.g. Galai and Geske 1984), and spillover effect both in terms of returns and volatility (Hamao, Masulis, \& Ng, 1990; Kearney \& Daly, 1998; Pyun, Lee, \& Nam, 2000). More recently, research explored the link between portfolio diversification and other aspects such as taxes (e.g. Stein et al. 2000) and leverage (e.g. Ruban and Melas 2011). Closer to our research are the works that focus on the role of currencies in portfolio diversification (e.g. Makin 1978; Pojarliev and Levich 2011) and the related spillovers (Johnson \& Soenen, 2004). The increasing presence of

${ }^{1}$ The first ever article on cryptocurrency (Bitcoin) on the Financial Times was published on $6^{\text {th }}$ June 2011 (Allowey, 2011) 
cryptocurrencies has started to attract some interest among academics who wish to assess bitcoin as an asset to include in portfolios. Sadly, very little has been published so far. There are few works that focus on spillovers (Burnie, 2018; Guesmi et al., 2018), on the correlation with other currencies (Baumöhl, 2018) or on cryptocurrency volatility (Katsiampa, 2017). In addition, few academics explore cryptocurrencies' liquidity and their investibility (Dyhrberg, Foley, \& Svec, 2018; Karalevicius, Degrande, \& De Weerdt, 2018; Wei, 2018), cryptocurrencies’ price formation (Brauneis \& Mestel, 2018; Ciaian, Rajcaniova, \& Kancs, 2015) or the relationship between cryptocurrencies and other financial assets (Corbet, Meegan, Larkin, Lucey, \& Yarovaya, 2018). Finally, very little research most of which is based on portfolios of U.S. assets, has been performed so far on portfolio diversification (Brière, Oosterlinck, \& Szafarz, 2015; Carrick, 2016; Wu \& Pandey, 2014). All in all, further investigation is very much needed.

Our study explores the bitcoin inclusion in three different geographically-defined portfolios of well diversified assets focusing on its effect on the risk-return. Thus, we examine three portfolios including U.S, European and Chinese assets, respectively. We have two aims: to explore whether bitcoin inclusion improves the performance of the portfolios of assets and whether bitcoin inclusion plays different role in different contexts. Thus, when we select assets to include in our analysis for each geographically defined area (i.e. the U.S., Europe and China), we include those that allow us to measure the performance of the portfolio for that specific area: in the case of U.S. portfolio, we include S\&P indices that measure the performance of U.S. firms, in the case of the European portfolio, we include the performance of European firms and in the case of Chinese portfolio we include only Chinese firms. The same applies to bonds. In order to do so we follow the approach of Brière et al. (2015). This approach differentiates our research from previous analysis focused on global portfolios (Bouri, Molnár, Azzi, Roubaud, \& Hagfors, 2017)

We use three different portfolio frameworks, namely naïve portfolio, the long-only portfolio, and the semi-constrained portfolio (Eisl, Gasser, \& Weinmayer, 2015). We also add a fourth 
portfolio (semi-constrained portfolio where bitcoin cannot be shorted) since, during the time span covered by our data, it was not easy to take short positions on bitcoin: regulated markets only launched derivatives on bitcoin which enables shorting strategies in late 2017 (Meyer, 2017). In the case of long-only and semi-constrained portfolios (with and without shorting), the weights are calculated using the mean-CVaR optimisation process (Eisl et al., 2015).

Our analysis suggests that bitcoin as an additional asset class in our portfolios tends to generate benefits in terms of increased returns and better performance of the portfolio measured using Risk-Return, Sortino and Omega ratios. In the time window considered (2013-2016), bitcoin generates higher returns but also higher volatility. However, the increased return tends to compensate for the increased volatility so that the performance overall improves. Interestingly, we discovered that the effects of inclusion are very positive and relevant in all the portfolios up to December 2013 while later the inclusion reveals a reduced effect in terms of return. We do not spot any major difference among the three geographical areas considered.

This manuscript is structured as follows: the next section explores previous research on bitcoin and portfolio diversification. Section 3 discusses the methodology and illustrates the variables used. Section 4 presents the descriptive statistics while section 5 reviews the separate results in the case of the U.S., European and Chines assets. Section 6 discusses the results and finally Section 7 concludes.

\section{Portfolio Diversification and Bitcoin}

To most ordinary people bitcoin remains a mystery: an intangible, and difficult-to-understand currency with little or no use in the real economy (Garcia, Tessone, Mavrodiev, \& Perony, 2014). Nakamoto (2008) in his whitepaper describes bitcoin as a peer-to-peer cash system where a system of nodes (distributed ledger) verifies whether the sender owns the funds they intend to spend and 
prevents double-spending (Böhme, Nicolas, Edelman, \& Moore, 2015; Nakamoto, 2008; Narayanan, Bonneau, Felten, Miller, \& Goldfeder, 2017). Thus, bitcoin operates without the need of financial intermediaries so that no central authority controls it (Böhme et al., 2015; Narayanan et al., 2017). The lack of a governance structure implies that there is no obligation to verify a user's identity, there is no prohibition on sales of particular items and payments are irreversible (Böhme et al., 2015). From the financial point of view, bitcoin's total supply and the rate of supply is pre-determined, nonelastic and fully transparent (Nakamoto, 2008). Since the rate of supply is pre-determined and continually decreasing bitcoin is inherently deflationary.

According to Keynesian economics, the demand for money is driven by three determinants: the precautionary demand, transaction demand, speculative demand. These in turn are driven by motives such as the need to save for a rainy day, holding money for daily transactions and the need for taking advantage of investment opportunities (Keynes, 1936).

Is bitcoin suitable as a store of value (i.e. driven by precautionary demand)? Bitcoin's 60 days average volatility over the six-year period (till early 2017) shows a steady decline but it remains much higher than that of gold and the traditional G10 currencies. Furthermore, bitcoin's return distribution exhibits stronger non-normal characteristics and heavier tails (Fry, 2018). Bouri, Molnár, Azzi, Roubaud, \& Hagfors (2017) suggest that bitcoin's distinctive volatility is due to the small size of the market and the trading volume even if Harvey (2017) has found no correlation between volatility and the market capitalisation prior to 2014 . However, given the highly volatile nature of bitcoin that makes it unsuitable as a store of value, its demand cannot be driven by the precautionary demand. This evidence leaves two alternative determinants of bitcoin demand: transaction demand (derived from trade transactions) and speculative demand (derived partly from exchange transactions).

Bitcoin transaction data is used by Kristoufek (2015) to show that an increase in trade volume is correlated with bitcoin price, suggesting that bitcoin appreciates in the long run if it is used more 
for transacting. In fact, the comparison of exchange-traded volume of bitcoin to total transaction volume within the bitcoin network suggests that most users (by volume) treat their bitcoin investments as speculative assets rather than as means of payment (Glaser, Zimmermann, Haferkorn, Christian Weber, \& Siering, 2014). Thus, bitcoin is only partially used a means of exchange. This implies that bitcoin's major driver is the speculative demand (derived partly from exchange transactions) and therefore it has to be considered an investible asset. However, it can be argued that bitcoin does not represent a proper asset class to invest in since it does not have an intrinsic value, neither it does generate any claim on future cash flows like a bond or equity nor has it any claim on future profit like in the case of shares. Nonetheless, this is not a proper justification for arguing that bitcoin is not an investible asset and research suggests that it is an asset (Corbet, Lucey, Urquhart, \& Yarovaya, 2018). In fact, bitcoin value changes according to demand and supply (Urquhart, 2017; Wei, 2018). Bitcoin is similar commodities like gold or silver (Dyhrberg, 2016b, 2016a) that even if they do not make any claim on a future cash flow, still have a value linked to their demand and supply and are perceived as assets that retain value in the long term irrespective of the evolution of the economy. This point is supported by quite a good number of bitcoin long term investors, also known as "hodlers", bitcoin long term investors (Kaminska, 2017). Bitcoin is also different with respect a piece of art or a rare stamp in the sense that it is characterised by a liquid, on line, electronic and de-personalised market where demand and supply form the price (Brauneis \& Mestel, 2018; Dyhrberg et al., 2018). Finally, recent research contests the older evidence that suggests bitcoin has not reached the investment grade status (Cheah \& Fry, 2015; Urquhart, 2016) arguing that, in fact, it is now in the mature stage and can be considered a proper asset class (Dyhrberg et al., 2018; Koutmos, 2018; Nadarajah \& Chu, 2017). Therefore, if bitcoin can be considered an asset characterised by a speculative demand (derived partly from exchange transactions), it may offer diversification benefits (Corbet, Meegan, et al., 2018; Guesmi et al., 2018). Thus, a related question emerges: is bitcoin an asset that could be included in an optimal portfolio? 
In fact, there is limited research on bitcoin (for a systematic review: Corbet, Lucey, et al., (2018). It moves from its pricing formation explores also whether bitcoin is an investible assets class, the link between bitcoin and other assets and its role as an asset in diversifying and hedge risk. Ciaian et al. (2015) and Kristoufek (2015) point out that the laws of supply and demand, as well as the market consensus among its adopters, play significant part in bitcoin price formation. Polasik et al. (2015) using a variety of methodologies, show that the demand factors affect bitcoin price formation significantly more than the supply side. Van Vliet (2018) finds evidence that bitcoin price follows Metcalfe's Law which states that the value of an asset depends on the network that uses it (the value being proportional to the square of the number of users). At the same time, Brauneis $\&$ Mestel (2018) suggest that price formation is affected by the liquidity that characterises the cryptocurrency while Urquhart (2017) finds that bitcoin pricing tend to cluster around zeros (that is rounded figures). Interestingly, liquidity is also found to affect cryptocurrencies' returns, with bitcoin that is the biggest gainer, as it is a very liquid cryptocurrency (Wei, 2018). The asset characteristic of cryptocurrencies is also supported by the fact that prices are found to be affected by media sentiment (Karalevicius et al., 2018) in line with previous research that explore sentiment's impact on price of traditional assets (e.g. Bhattacharya \& Ritter, 1983; Wisniewski \& Moro, 2014).

Cryptocurrencies present high volatility (Katsiampa, 2017) so that they are considered typically high risk investment. Interestingly, cryptocurrencies are mainly traded by private investors and only more recently by professional ones but not by way of algorithms, (Dyhrberg et al., 2018), suggesting that cryptocurrencies in general and bitcoin in particular are investible assets (Phillip, Chan, \& Peiris, 2018). Researchers who focus on bitcoin correlation with other assets find that cryptocurrencies have a relatively low correlation with other assets, which might suggest bitcoin as an asset that can help in portfolio diversification (Baumöhl, 2018). This point is also supported by Corbet et al. (2018) who discover relative isolation of cryptocurrencies from other financial assets and by Bouri, Naji, Molnár, \& Roubaud (2017) who find that bitcoin is a good hedge against 
movements in commodities indexes. The potential benefit of including bitcoin in a portfolio is also supported by research that explores spillovers between bitcoin and other assets (Burnie, 2018; Guesmi et al., 2018) since it is found to allow for hedging risk. All in all, the reported research suggests that bitcoin is an asset class that can be included in a well-diversified portfolio.

Actually, little research typically based on portfolios of U.S. assets, has been performed so far on portfolio diversification including bitcoin or cryptocurrencies in general (e.g. Adrianto \& Diputra, 2017; Bouri et al., 2017; Brière et al., 2015; Carrick, 2016; Guesmi et al., 2018; Wu \& Pandey, 2014). One of the oldest works by Eisl et al. (2015) show that including bitcoin in an already diversified portfolio of U.S. assets increases both the expected return and the risk of the portfolios. They suggest a possible allocation of bitcoin in such portfolio to maximise the Sharpe Ratio. Brière et al. (2015) show that by adding bitcoin to an already diversified portfolio of U.S. assets, the Sharpe Ratio (Sharpe, 1963) improves. Bitcoin is found to increase the efficiency of portfolios when tested against other measures, such as the Omega Ratio (Wu \& Pandey, 2014) and variations of the Sharpe ratio where $\mathrm{VaR}$ and $\mathrm{CVaR}$ replace the standard deviation as a measure of risk (Eisl et al., 2015). More recent research provides further support arguing that an optimal mix of bitcoin and U.S. equities can reduce the overall risk of a portfolio (Bouri, Molnár, et al., 2017). Interestingly, similar results are obtained in portfolios that include foreign currencies, commodities, stock and ETF (Adrianto \& Diputra, 2017) as well as portfolios including global and emerging market indices (Guesmi et al., 2018).

However, bitcoin's financial characteristics, such as volatility, have evolved considerably since the "crash" of 2013, when some of the earlier properties that made it a safe haven completely disappeared (Kristoufek, 2015). This implies that bitcoin's qualities as a diversifier might also have been affected. More importantly, the quoted empirical studies either adopt the perspective of a U.S. investor or that of a global investor. Incidentally, in different specific markets bitcoin trading activity 
and the adoption rates are very different. In fact, historical data ${ }^{2}$ from data.ity.org shows that the proportion of bitcoin bought and sold, for instance, in China has steadily grown over the years and as of September 2017 comprises of $\sim 99 \%$ of all bitcoin exchange transactions globally, whereas USD transactions have remained relatively stagnant in comparison, amounting to less than $1 \%$ of global exchange volume ${ }^{3}$. Consequently, events happening in the wider Chinese economy directly affect the CNY bitcoin market which in turn can have a significant impact on the USD market (Kristoufek, 2015). A similar situation can be quoted for the European markets and assets. Thus, it is important to explore whether the benefits linked to bitcoin inclusion can be affected by the localisation of the portfolios. Currently no research explores differences in the role of bitcoin in portfolio diversification in European and Chinese assets while the research on U.S. is very much limited.

\section{Methodology and Data}

The nature of this research is primarily explorative. It employs a variation of the established Modern Portfolio Theory (Markowitz, 1952, 1976) to estimate parameters and draw conclusions from historical data. The analysis will focus on the effects of adding bitcoin to an already diversified portfolio, or more precisely the effects that it might have on the return and risk of such portfolios. The analysis requires us to build efficient frontiers of portfolios where bitcoin is present and comparing it to portfolios where ceteris paribus, bitcoin is not present. The efficient frontier comprises of all the possible portfolios which can be constructed from a given pool of assets where the return is maximised given the desired risk. We use terms 'optimal' and 'well-diversified' interchangeably throughout this work to refer to such portfolios. We follow Eisl et al. (2015) by

\footnotetext{
${ }^{2}$ Accessed on $12 / 09 / 2017$

3 It is important to point out that in September 2017 China regulators forbade the use of Bitcoin and Bitcoin trade. Even if Chinese population can informally access Bitcoin via foreign platforms, we cannot rule out that, as far as Chinese market findings are concerned, our results can be somehow affected by the new limitations.
} 
constructing portfolios in different optimisation contexts, described in more detail below. We then repeat the process but with an asset pool that contains bitcoin. The portfolios are subsequently compared to see if adding bitcoin has any effect on portfolio weights and the portfolio risk-return ratio in respect of the optimisation procedure used.

Scenario 1: Nä̈ve (equal weights) Portfolio $\left(w_{i}=\frac{1}{N} \forall i\right)$

The naïve portfolio is constructed so that all assets are allocated equally irrespective of potential effects on the risk-return ratio. In their landmark study, DeMiguel et al. (2007) have shown that a portfolio where asset allocation is calculated using the mean-variance optimisation procedure, performs no better than an equal weight portfolio consisting of the same pool of assets in terms of Sharpe Ratio (Sharpe, 1963, 1964). It would therefore be interesting to see what kind of effect bitcoin might have in this scenario and if such an effect is any different from the one observed in other scenarios. Since no part of the sample data is used to estimate optimal weights, the out-ofsample period equals the entire 60-month sample period.

Scenario 2: Long-Only Portfolio $\left(w_{i} \in \mathbb{R}^{+}: \sum w_{i}=1\right)$

This optimisation process allows no shorting and effectively limits the individual weights to $100 \%$. The long only portfolio represents a more feasible option for investors given the context; and the asset weights should also be more stable when re-balancing. Since the first 12 months are used to determine portfolio weights, the explored sample period is 12 months shorter than the total sample period.

Scenario 3: Semi-constrained Portfolio $\left(w_{i} \in \mathbb{R}:-1 \leq w_{i} \leq 1: \sum w_{i}=1\right)$

Here, the optimisation process seeks to maximise the risk-return ratio of a portfolio, without placing any weight-related constraints on assets not allowing leveraging, as such it should yield a better risk-return ratio than other scenarios except for the unconstrained portfolio.

Scenario 4: Semi-constrained Portfolio with No Shorting on bitcoin $\left(w_{i \neq b t c} \in \mathbb{R}, w_{b t c} \in \mathbb{R}^{+}\right)$

Though hypothetically it is possible to short bitcoin, there is limited evidence at present and it 
is linked to financial products that are typically over-the-counter. Thus, we estimate a portfolio where all the assets but bitcoin can be shorted. The results of this strategy might therefore be rendered purely theoretical should the optimisation procedure demand that bitcoin is shorted.

It can be argued that it is also possible to build up unconstrained portfolios, that is a portfolio with no restrictions on asset weights, so that both shorting and leveraging are allowed. This type of optimisation is expected to result in extreme long or short positions which might not be implementable in the real world, due to large initial weights in either direction (short or long) and subsequent shifts in weights during re-balancing. In fact, we test this portfolio and we end up with large leverages that cannot be implemented in real life. Thus, we decided not to present these portfolios in the current analysis.

\subsection{The Mean-CVaR approach}

For all scenarios except naïve, we adopt a variation of Markowitz's Modern Portfolio Theory (Markowitz, 1952) as basis for constructing efficient portfolios, where an efficient portfolio is defined as the one that achieves maximum expected return for a desired level of risk. Under the original model, the expected return is simply the weighted average of constituent asset returns and the risk, which is measured by the portfolio variance $\sigma_{p}^{2}$, and is a function of the correlations $\rho_{i j}$ of constituent assets, for all asset pairs $(i, j)$ (Markowitz, 1952). The main disadvantage with the meanvariance approach is that it oversimplifies the risk-preferences of investors. Variance is a symmetric measure that incorporates both the upside and the downside volatility, whereas in the real-world, assuming investors are rational, only the downside component is undesirable.

An alternative risk measure proposed in literature is the Value-at-risk (VaR). It is an asymmetric measure that is expressed as a minimum loss value (or percentage) for a given probability and time horizon. VaR's main limitation is that it only estimates the minimum potential loss and does not quantify the amount this threshold could be exceeded by potentially underestimating the tail risk. The Conditional Value at Risk (CVaR), or as it is also more commonly 
known, the Expected shortfall (ES) addresses this problem by calculating the expected return (average loss) beyond the VaR threshold (Alexander \& Baptista, 2004) and it has been previously used to portfolio optimisation (e.g. Silvapulle and Granger 2001; Topaloglou et al. 2002). Acerbi and Tasche (2002) have shown that CVaR/ES offers a number of advantages over VaR, without giving up any of its original attractions. $\mathrm{CVaR} / \mathrm{ES}$ is often described as a coherent measure of risk, because it satisfies a set of four desirable properties, namely: Monotonicity, Translation invariance, Homogeneity and Sub-additivity (Artzner, Delbaen, Eber, \& Heath, 1999) whereas Variance and VaR do not.

We adopt the Conditional Value at Risk $(\mathrm{CVaR})$ as the measure of portfolio risk which we calculate for each asset at the $\alpha=5 \%$ confidence level.

$$
C V a R_{p}^{2}=\sum_{i} \sum_{j} w_{i} w_{j} C V a R_{i} C V a R_{j} \rho_{i k}
$$

From which, portfolio risk is derived:

$$
\operatorname{CVaR}_{p}=\sqrt{\mathrm{CVaR}_{p}^{2}}
$$

The optimisation procedure for non-naïve scenarios will therefore seek optimal asset weights that maximise the risk-return ratio, provided that the listed constrains for each scenario are met as prescribed.

$$
\max \left(\frac{E\left(R_{p}\right)}{C V a R_{p}}\right)
$$

Calculating portfolio risk using this approach requires that we know the CVaR of individual assets used in the optimisation process. There are various methods for calculating the CVaR, the most common being the variance-covariance, stochastic and empirical methods. Skewed distributions make the historical/empirical approach the preferred method for the purpose of our research (note that bitcoin returns exhibit a pronounced positive skew). The main advantage of this method is that it does not make assumptions of normality, since the distribution is inferred from 
historical data. The downside of this strategy of course is that it assumes that future distributions maintain the same skew over time. Using the 12 month in-sample daily data and for each asset, we calculate monthly moving averages $(M A)$ of daily returns, resulting in 261 data points. CVaR is then calculated as the simple mean of all the observations on and below the Value-at-Risk (VaR) threshold at the $\alpha=5 \%$ confidence interval, or the $5^{\text {th }}$ percentile of the calculated monthly moving average returns:

$$
C V a R=\frac{1}{N} \sum_{i=1}^{N} M A: M A \leq V a R
$$

It can be argued that alternative optimisations approaches are available. However, in the case of portfolios with Bitcoin it has been shown that the results for the period up to the end of 2017 are not affected by the portfolio optimisation approach used (Platanakis \& Urquhart, 2018).

\subsection{Evaluating Portfolio Performance}

We divide back-testing in two parts. The first part assesses whether the initial weights $w_{i}$ calculated during the optimisation process are robust over the entire sample investment period without any rebalancing. The second part examines the performance of portfolios over the entire sample period but with semi-annual weight rebalancing (eight times in total for the four years period). This technique, with respect the alternative approach (e.g. Platanakis and Urquhart (2018) use weekly rebalancing), allows us to appreciate the extent of the rebalancing of the portfolio. In fact, frequent rebalancing does not allow us to understand the magnitude of the final adjustment of the portfolio. Since we have only eight rebalances, we do not include the transaction costs linked to them because of their very reduced impact.

In order to calculate the Risk-Return ration we calculate the out of the sample return and CVaR for both the portfolio with and without rebalancing. Using these data, we derive and observe monthly Risk-Return (RR) performance defined as: 


$$
\mathrm{RR}_{m}=\frac{\bar{R}_{p}-\bar{R}_{f}}{\operatorname{CVaR}_{m}}
$$

The aforementioned approaches have their limitations since they depend on portfolio mean and variance and can have difficulties in providing robust and correct results when returns are not normally distributed (Smetters \& Zhang, 2014). Thus, we also estimated the Sortino ratio (Sortino \& van der Meer, 1991) that consider the standard deviation of only the downside excess returns, defined as

$$
\text { Sortino }=\frac{\bar{R}_{p}-\bar{R}_{f}}{D R_{p}}
$$

where $D R_{p}$ denotes the downside excess return. We also estimate the Omega ratio (Keating \& Shadwick, 2002) which represents the ratio between the average gain and the average loss (with target return set to zero following the Bernardo and Ledoit (2000) special case of the Gain-Lossratio), defined as

$$
\text { Omega }=\sum_{t=1}^{T} \max \left(0,+R_{t}\right) / \sum_{t=1}^{T} \max \left(0,-R_{t}\right)
$$

The advantage of the Omega ratio is it does not assume Normal distribution.

\subsection{Data}

\subsubsection{The Bitcoin Price Index}

We construct the bitcoin USD Price Index (BTCUSD), EUR Price Index (EURBTC) and bitcoin CNY Price Index (BTCCNY) using data from data.bitcoinity.org, which in turn derives its data from the publicly available raw blockchain ${ }^{4}$ data. Historical data for bitcoin starts on $18^{\text {th }}$ July 2010 , however, the early period of bitcoin's trade is characterised by very low trading volumes and

${ }^{4}$ The blockchain is the distributed public ledger of all the historical bitcoin transactions. 
liquidity which does not significantly improve until 2012. Thus, we choose February 2012 as the start date of the sample period. Our analysis stops on $31^{\text {st }}$ January 2017 , covering 60 months of daily returns. We also exclude the observations since $1^{\text {st }}$ February 2017 due to very unusual performance exhibited by bitcoin: it passed 1,000USD on $3^{\text {rd }}$ January 2017 reaching 17,900USD in December 2017. The outstanding performance has been considered by the financial community a typical example of a bubble that, partially, exploded in the first months of 2018. Research suggests that a financial bubble can be defined as “[ $[\cdots]$ dramatic asset price increases followed by a collapse. Bubbles arise if the price exceeds the asset's fundamental value. This can occur if investors hold the asset because they believe that they can sell it at a higher price to some other investor even though the asset's price exceeds its fundamental value.” (Brunnermeier, 2016). Interestingly, this description matches bitcoin's 2017 behaviour. In addition, not only is bitcoin's 2017 performance characterised by rapidly increasing prices, but during the year press and blogs where full of stories that purport to justify the bubble with people feeling envy and regret they are not a part in the rally. These are further aspects that characterize a bubble (Fox, 2014). Finally, mathematical and empirical analysis also stresses the bubble stage of bitcoin in 2017 (Cheah \& Fry, 2015). We argue that the inclusion of such a "bubble" period can introduce a bias in a long period analysis of the benefit of bitcoin inclusion in a portfolio of well diversified assets. In other words, the bitcoin performance in 2017 can generate a portfolio with a large proportion of bitcoin in it that can largely outperform the portfolio without bitcoin. The real long-term portfolio effect of such "bubble" can be appreciated only by including the subsequent corrections in value that bitcoin has since experienced. However, we believe to be too soon to include the period for the purpose of exploring real long-term effects.

\subsubsection{Other asset classes}

To allow for creation of a well-diversified portfolio, we sample a broad range of assets available to US, Europe and Chinese investors consisting of equities, fixed income, commodities, real estate, cash equivalents, currencies, and alternative investments. Each of these asset-classes is 
represented by a liquid investible index, most of which are denominated in the local RMB, EUR or USD currency.

Table1, shows a detailed overview of assets which will be used in the optimisation process.

\section{TABLE 1 HERE}

The construction of three different portfolios allows us to explore whether bitcoin inclusion has different "local" effects, that is whether it has different impact on portfolio diversification according to whether it interacts with Chinese, U.S. or European assets.

\section{Descriptive statistics}

The tables $2 \mathrm{~A}, 2 \mathrm{~B}$ and $2 \mathrm{C}$ below show the descriptive statistics of the excess monthly returns ${ }^{5}$ of assets included in the portfolios used in the optimisation process in the case of the U.S., European and Chinese assets.

TABLE 2A HERE

TABLE 2B HERE

TABLE 2C HERE

\footnotetext{
${ }^{5}$ The returns used in the analysis are net risk free rate. This explains the differences between values in US and China markets of the same asset class (e.g. bitcoin)
} 
In line with the previous studies by Eisl et al. (2015) and Wu and Pandey (2014), bitcoin exhibits large kurtosis and is positively skewed, albeit to a much lesser extent than previously reported (Figure 1A, 1B and 1C)

FIGURE 1A HERE

FIGURE 1B HERE

FIGURE 1C HERE

The correlation coefficients are reported in Table 3A, 3B and 3C and the evolution of bitcoin with respect other assets in Figure 2A, 2B and 2C.

TABLE 3A HERE

TABLE 3B HERE

TABLE 3C HERE 
FIGURE 2A HERE

FIGURE 2B HERE

FIGURE 2C HERE

As far as the U.S. assets are concerned, bitcoin presents correlations with the largest part of the other indices. Interestingly, it shows a fairly high correlation with the Standard and Poor index (positive) while the highest negative correlation is with gold. This is in contrast with earlier works by Eisl et al. (2015) and Wu and Pandey (2014) that do not report significant correlations with any of the U.S. assets indices. Similarly, it is at a variance with the detailed analysis on bitcoin correlation performed by Baumöhl (2018). The difference can be ascribed to a different time window: Eisl et al. (2015) and Wu and Pandey (2014) look at the early stage of bitcoin (that presented quite high volatility and a very high increase in its value); Baumöhl (2018) includes in his analysis 2017, when the huge increase in bitcoin was completely decoupled from the performance of any other asset in the market. In terms of evolution thorough time Figure 2A, shows the returns of bitcoin and other assets. It is evident how much more "erratic" are bitcoin returns. In addition, bitcoin returns tend to be decoupled with respect to the behaviour of the returns of other assets.

In the case of the European assets, bitcoin shows a relatively high and significant correlation with the hedge fund index (HFRX) and small but statistically significant positive correlations to all the European assets' indices except for the S\&P Pan-Europe Developed Sovereign Bond Index, Dow Jones Europe Select Real Estate Securities Index and S\&P EURO Futures Index Spot. In terms of evolution thorough time Figures 2B, show the return of bitcoin and other European assets. The graph 
is very similar to the bitcoin/U.S. assets one: bitcoin is more "erratic" and decoupled with respect the behaviour of the returns of other assets.

In the case of the Chinese assets, bitcoin shows small but statistically significant correlations to all the Chinese assets' indices except for the China Mid-Cap, Small-Cap equity indices and the Guggenheim China Real Estate ETF (TAO). The results are in line with the U.S. and European correlations. A significant negative correlation exists between bitcoin and the Chinese government bill index (billcn), and a somewhat weaker but still significant negative correlation with the China Sovereign bond (conden) and corporate bond (corpen) indices, suggesting that bitcoin could be used by some investors in China as a safe haven during events that adversely affect the prices of these assets. In terms of evolution thorough time Figure $2 \mathrm{C}$, shows the return of bitcoin and other Chinese assets. The graph is very similar to the previous one confirming the fact that bitcoin is also more "erratic" with respect to Chinese assets and its returns; and decoupled with respect to those of other assets.

\section{Analysis}

In this section, we examine the bitcoin portfolios linked to the different areas: first we explore the role of bitcoin in the case of portfolios of U.S. assets, the European ones and those comprising Chinese assets. The last part of the analysis compares the results exploring similarities and differences in the use of bitcoin in the three areas.

\subsection{U.S. Assets and Bitcoin}

The initial weights of the optimisation process (not reported here) show the semi-constrained portfolios with a small weight of bitcoin relative to other assets. When applying semi-annual rebalancing (Table 4) to a long-only portfolio, the weight of bitcoin shows a progressive decline averaging at $5.47 \%$ for the duration of the investment period. 
TABLE 4 HERE

Both the semi-constrained/bitcoin long-only portfolios present an average proportion of bitcoin of $2.88 \%$ but with proportions between $.01 \%$ to $8.19 \%$. As far as the semi-constrained portfolio is concerned, no shorting emerges in the optimisation process. Thus, the weight of bitcoin in the semi-constrained and semi-constrained (no shorting on bitcoin) is the same. We tried (not reported here) with the unconstrained portfolio (i.e. a portfolio that allows for both shorting and leveraging without any limit). In doing so we obtain large adjustments during the period (from $16.76 \%$ to $+16.21 \%$ ) but not as large as in the case of Chinese and European portfolios (see later comments).

In order to have a clearer idea of the performance of a portfolio with bitcoin, we run backtesting: first without any rebalancing, and then with semi-annual rebalancing using the same optimisation technique used to calculate the initial weights (Table 5A and Table 5B).

\section{TABLE 5A HERE}

\section{TABLE 5B HERE}

In portfolios where no rebalancing is applied, the results indicate that adding bitcoin to portfolio of U.S. assets is beneficial in all the cases except in the case of the semi-constrained portfolio where the average return goes down by $6.67 \%$. In terms of risk, volatility increases in both the naïve and long-only portfolio while it decreases in the case of the semi-constrained portfolio. When we look at Risk-Return, Sortino and Omega ratios all the portfolios benefit from bitcoin 
inclusion. In fact, in the case of naïve and long-only portfolios there is an increase in the return that overcomes the increase in the volatility of the portfolio; in the case of the unconstrained portfolio, performance improvements are linked to the reduction in the volatility of the portfolio of assets.

Semi-annual rebalancing is applied, the results show the positive effect on return in the case of the long-only portfolio. In terms of performance the Risk-Return ratio improves in all the portfolios. However, in the case of semi-constrained portfolio the average Omega ratio moves from 3.0031 to 1.8159 and the Sortino ratio worsens from 4.0466 to 1.8454 .

We also explore how often the portfolio with bitcoin out-performs the portfolio without bitcoin. In the case of the no rebalancing, the naïve portfolio with bitcoin out-performs that one without bitcoin in $65.70 \%$ of the observations, while in the case of long-only and semi-constrained portfolios the percentages decrease to $54.77 \%$ and $54.23 \%$ respectively. When we look at the portfolio with semi-annual rebalancing, the portfolios with bitcoin outperform those without bitcoin in 54.77 in the case of long portfolio and in $54.23 \%$ of the cases in the case of semi-constrained ones. The results suggest that the benefit bitcoin generates relies on good returns in relatively high number of days that compensate for poor returns in a relatively low number of days.

Finally, we explore the performance of the portfolios for subperiods (years) in order to explore whether bitcoin benefit is linked to a specific period (detailed tables not reported here). The analysis suggests that the benefit generated by bitcoin in terms of returns is mainly due to a majority of very good performance in 2013 when the effects of inclusion are significantly positive in naïve and long-only scenarios $(4.12 \%$ and $6.29 \%$ average daily return with respect to $0.57 \%$ and $0.10 \%$ average return of the portfolio without bitcoin). This result partially supports the earlier findings (Eisl et al., 2015) that suggest that bitcoin improves the Risk-Return ratio in all scenarios if added to an optimal portfolio of western assets. A divergence can be observed in the period after December 2013 when the inclusion reveals marginal effects in terms of the return ratio in all portfolios. In terms of risk (volatility of the portfolio), the results suggest that inclusion of bitcoin increases it in all the 
portfolios in 2013 and 2016.

\subsection{European Assets and Bitcoin}

In the initial optimisation process, only the long-only portfolio results in significant amounts of bitcoin: in the semi-constrained portfolio the weight of bitcoin relative to other assets is relatively small and remains small with semi-annual rebalancing. When applying semi-annual rebalancing to long-only portfolios the weight of bitcoin faces large changes (between $0 \%$ and $56.31 \%$ ). In the semi-constrained portfolio bitcoin has an overall minor yet stable role. We also attempted analysis of the unconstrained portfolio. We end up with rebalancing in terms of bitcoin between $-10.18 \%$ and $104.97 \%$ that cannot be easily implemented.

TABLE 6 HERE

The back-testing results for the European markets portfolios with and without rebalancing are reported in Table $7 \mathrm{~A}$ and $7 \mathrm{~B}$

\section{TABLE 7A HERE}

TABLE 7B HERE

Without rebalancing (Table 7A), the results in terms of return indicate that adding bitcoin to a portfolio of European assets is beneficial in all the cases. However, all the portfolios show an increase in the volatility, as well. In terms of performance, Sortino and Omega ratio suggest a benefit linked to bitcoin inclusion in all the portfolios strategies while in the case of Risk-Return of the semiconstrained portfolio there is a decrease of the ratio from .03 to .02 . The improvement in the 
performance (Risk-return, Sortino and Omega ratios) of the majority of the portfolios has to be ascribed to the increase in the returns that compensate for the increase in the riskiness (volatility) of the portfolio. The analysis of the performance of the portfolio with rebalancing (Table 7B) shows that in all the cases the portfolio with bitcoin grants higher returns than those without bitcoin. At the same time all the portfolios face an increase in the volatility. Nevertheless, Risk-Return, Omega and Sortino improves in all cases where bitcoin is added. If anything, findings are stronger than the results we obtain on the portfolio without rebalancing where the improvement in performance (RiskReturn, Sortino and Omega ratio) has to be ascribed to the increase in the returns that more than compensate for the increase in the risk of the portfolio.

As in the case of the US analysis, we also explore how often the portfolio with bitcoin outperforms the portfolio without bitcoin. Without rebalancing, the naïve portfolio with bitcoin outperforms that without bitcoin in $65.59 \%$ of the cases; the long only and the semi-constrained portfolios with bitcoin outperform the portfolio without bitcoin in $63.34 \%$ of the case. With rebalancing, the evidence suggests that the portfolio with bitcoin outperforms the one without bitcoin in $54.56 \%$ of the cases in the long only strategy, in $33.04 \%$ of the cases in the semi-constrained and in $35.05 \%$ in the case of semi-constrained with no shorting on bitcoin. In this case evidence suggests that when rebalancing is included, the superior performance of portfolios that include bitcoin with respect those that do not is linked to a very high returns in a relatively small number of days.

Finally, we explore the performance of the portfolios for subperiods (table not reported here). The inclusion of bitcoin in 2013 increases the performance in all the portfolios (between $2.68 \%$ and $40.23 \%$ ) and the same applies in the case of 2014 even if the benefit is less marked (between $.68 \%$ ad 8.01\%). A divergence can be observed in the period after December 2013 where the inclusion reveals marginal effect in terms of the return in any scenario. As far as the volatility is concerned, bitcoin inclusion increases it in naïve portfolio for all the years except in 2016. For other portfolios, bitcoin tends to decrease it. In terms of risk-return, bitcoin inclusion improves it in the case of the naïve 
portfolio while in the case of other portfolios, the results are mixed with a decreasing benefit as the time goes by. For instance, bitcoin inclusion appears less beneficial in the case of semi-constrained portfolio where the Risk-Return ratio improves only in the second year while in the case of semiconstrained (no shorting) it improves marginally during the same period. Our empirical evidence partially supports earlier findings (Eisl et al., 2015) that suggest that bitcoin improves the return in all scenarios if added to an optimal portfolio of western assets.

\subsection{Chinese Assets and Bitcoin}

The initial optimisation process suggests the inclusion of a significant proportion of bitcoin in the long-only portfolio only. The semi-constrained portfolio has a proportion of bitcoin that is relatively small. When applying semi-annual rebalancing (table 8) to a long-only portfolio, the weight of bitcoin is reduced to a relatively minor proportion.

TABLE 8 HERE

As in the previous cases, the back-testing has been implemented twice and the results are reported in Table 9A and 9B

\section{TABLE 9A HERE}

\section{TABLE 9B HERE}

Turning our attention to the return of the portfolio with Chinese assets, in the case of no rebalancing (Table 9A), both the naïve and the long-only portfolios present improvements with respect the portfolio without bitcoin. At the same time, the semi-constrained portfolio seems to be 
adversely affected by bitcoin inclusion. However, the semi-constrained portfolios enjoy a reduction in the risk with a $12 \%$ decrease in volatility. In terms of portfolio performance, naïve and long only benefit from an improvement on the Risk-Return, Sortino and Omega ratio while in the case of the semi-constrained portfolio the performance outputs mixed results: Risk-Return and Sortino ratio improve while the Omega ratio worsens (even if only marginally). When semi-annual rebalancing is applied, the results show a positive effect on the return of all the portfolio except the semi constrained one that faces a decrease from $.82 \%$ to $.77 \%$. In terms of performance, the long-only presents an improvement on all the metrics while the semi-constrained faces a worsening in the case of the Sortino ratio. Interestingly, in the case of the semi-constrained portfolio, the improvement in the performance is mainly linked to the reduction in the volatility while in the case of the naïve, the better performance is mainly to be ascribed to the improvement in the return that compensates for the increased volatility. Finally, the semi-constrained portfolio with no shorting on bitcoin faces a worse Omega and Sortino ratio with no change in the Risk-Return one.

In terms of comparative performance, the bitcoin portfolios without rebalancing present returns higher than those without bitcoin in between $44.80 \%$ of the cases (semi-constrained) and $66.35 \%$ of the cases (long-only). When re-balancing is applied, the portfolio with bitcoin outperforms that one without bitcoin in $59.38 \%$ of the observations in the case of the long only while the semi-constrained portfolio with bitcoin outperforms the portfolio without bitcoin in $51.34 \%$ of the observations.

Finally, we explore returns and risk of the portfolios in the subperiods. In line with evidence from portfolios with European and U.S. assets, during this year, the effects of inclusion are significantly positive in naïve and long-only scenarios $(3.54 \%$ and $14.96 \%$ average daily return with respect $.45 \%$ and $-.13 \%$ average return of the portfolio without bitcoin). Divergence can be observed in the period after December 2013 where the inclusion reveals limited effect in terms of the RiskReturn ratio in any scenario: the portfolio with bitcoin over-performs marginally and occasionally it 
underperforms. As far as volatility is concerned, bitcoin inclusion decreases it in all the portfolios in 2013 while in the following years the result is more varied: in 2014 naïve and long-only portfolio do not benefit from bitcoin inclusion while in 2015 this is only the case for naïve portfolio. Finally, in 2016, only the semi-constrained portfolio gains from a reduction in its volatility for all the years. Also, in this case, our empirical evidence provides partial supports the earlier findings (Eisl et al., 2015) which suggest that bitcoin improves the return in all scenarios if added to an optimal portfolio of western assets even if they are less supportive than in the case of U.S. and European assets.

\section{Discussion}

The analysis is quite conclusive: (i) the inclusion of bitcoin tends to improve the return of the portfolios in the largest majority of cases; (ii) only in the case of US and Chinese semi-constrained portfolios without rebalancing and in the case of the US semi-constrained portfolio with rebalancing the return of the portfolio including bitcoin decreases. In other words, only in 3 cases out of the 21 different portfolios we examined bitcoin does inclusion worsen portfolio return. At the same time, the portfolios enjoy a reduction in term of volatility only in the case of the China semi-constrained portfolios with and without rebalancing and in the case of the US semi-constrained portfolio with rebalancing. Thus, we can conclude that if bitcoin improves the return, it also increases the riskiness of the portfolios. However, in terms of overall performance, the results tend to support the idea that bitcoin improves the portfolio of diversified assets. In fact, it improves the Risk-Return ratio in all the portfolios but two (EU - semi-constrained with/without shorting in "without rebalancing" case); the Omega ratio in all the cases but that of China semi-constrained (with/without shorting with/without rebalancing) and in the case of US semi-constrained (with/without shorting without rebalancing), that is in 6 cases out of 21 scenarios. Finally, the Sortino ratio improves in all the portfolios without rebalancing and worsens only in the case of US and China semi-constrained 
(with/without shorting) with rebalancing, that is in 4 cases out of 21. All in all, out of 63 performance measurements, we have 11 cases where the performance worsens (i.e. $17.5 \%$ of the cases).

The results in terms of annual (subperiod performance) performance are quite consistent among the three contexts under investigation. More in detail, in the case of the long portfolios, the results are always consistent. In the case of naïve portfolio there is only one case (Chinese portfolio in 2015) where the result is different with respect the other two contexts. A lower level or consistency emerges in the case of unconstrained portfolios ${ }^{6}$ and in the case of semi-constrained portfolios $^{7}$. In terms of risk $(\mathrm{C}-\mathrm{VaR})$, the results are very consistent among the three contexts. The only investment strategy that presents different results among the three contexts is the semiconstrained portfolio. Thus, we can conclude that there are no major differences in the inclusion of bitcoin in the portfolios of U.S., European of Chinese assets.

An interesting aspect to consider is the evolution of the role of bitcoin through time: there is a difference between the role of bitcoin prior to December 2013 and the subsequent period until the end of 2016. During this early period, the effects of inclusion are significantly positive in all the portfolios. However, this changes at the beginning of 2014 when portfolios with bitcoin underperformed those without in 15 out of 45 cases. We can conclude that the benefit linked to bitcoin's inclusion is mainly linked to a quite specific period (2013) and to the fact that in 2013 bitcoin showed a marked increase in its value.

All in all, our evidence suggests that bitcoin plays a relevant role in portfolios diversification: it is consistent in generating benefits linked to the increase in the returns while it has a more marginal role in decreasing volatility. More in detail, the inclusion of bitcoin consistently generates benefits in

${ }^{6}$ (Chinese portfolios generate a different result with respect U.S and European ones in three cases while the U.S. portfolios generate a different result with respect European and Chinese ones in one case)

${ }^{7}$ (U.S. portfolios generate a different result with respect Chinese and European ones in two cases while the European portfolios generate a different result with respect U.S. and Chinese ones in one case) 
the portfolios' performance in naïve and long portfolios both with and without rebalancing. The results are mixed in the case of semi-constrained portfolios. In addition, the overall benefit in the time window considered in the analysis can be mainly ascribed to the result of the high return obtained in 2013 since the benefits of bitcoin in the following years are not systematic and definitely reduced when compared with 2013. However, our results are partially in line with the previous findings and tend to suggest the current speculative nature of bitcoin as an asset class. ${ }^{8}$

So, as far as portfolio managers are concerned, which is the best investment strategy for a portfolio including bitcoin? If rebalancing has to be avoided, the best strategy in terms of absolute returns seems to be the naïve one for the US $(0.96 \%)$ and the long only in the case of EU $(2.56 \%)$ and China (3.13\%). However, if we look at the improvement that can be obtained from bitcoin inclusion, the picture is marginally different since the portfolio that benefits most from bitcoin inclusion is the long one in all the contexts under investigation. When we look at the portfolio with rebalancing, the best strategy is the long one for all the contexts under investigation. All in all, shorting assets as well as shorting bitcoin even when it generates benefit, does not outperform the long only portfolio. The (under)performance of the portfolios where shorting is included compared to the long-only portfolios and especially the naïve portfolio is at least partially in line with the work by DeMiguel et al. (2007) that show that naïve portfolios often perform better than optimised portfolios in general.

\footnotetext{
${ }^{8}$ An important caveat must be stressed: the portfolio allocation suggested by our analysis cannot necessarily be implemented. The major problem is linked to the fact that the bitcoin market is not very liquid in the sense that buying and selling large amounts of bitcoin can be problematic. Currently there is a relatively low number of websites where bitcoin can be traded; occasionally they struggle to satisfy investor requests; it is not unusual to find substantial differences in the exchange rate applied by different website (suggesting good possibilities for arbitrage but the low liquidity of the market). This can adversely affect the possibility of implementing the semi-annual adjustments when they imply a large reduction/increase in the amount of bitcoin to include in the portfolio: the investor may struggle to buy the amount of bitcoin that they want to add to their portfolios; similarly, they can discover that by selling the bitcoin the price can drop dramatically. However, more frequent rebalancing (e.g. weekly as suggested by Platanakis and Urquhart (2018) or monthly that implies smaller adjustments) can suggest portfolios that can be implemented even if in those cases the portfolio performance can at least partially compromised by the increase in the transaction costs.
} 
Our analysis clearly suggests that portfolios' improved performances compensate for the higher risk incurred because of bitcoin inclusion. However, the increase in the risk of then portfolios raise the question whether authorities should take any action in order to protect investors. In fact, regulators cannot intervene in any way on bitcoin price formation since it is not under the control of any authority by design. However, regulators have the power to set up rules that limit the possibility for any regulated investment tool (e.g. trust funds, insurance policies, pension funds, etc.) to invest in bitcoin (e.g. the case of KodakCoin and the need for Kodak to check the status of individual accredited investors for 40,000 potential investors in order to follow the SEC regulation). They can even limit possibility of trading in bitcoin (something similar to what has been done recently by the Chinese and Korean governments). Thus, the question is: should regulators intervene?

According to our results, bitcoin (and, possibly, all the cryptocurrencies) seem to be assets that have to be handled with care (along the lines of SEC limitation on KodakCoin investors). However, at this stage we know too little about all the cryptocurrencies and their behaviours: even though the amount of data appears overwhelmingly large (detailed prices and volumes for bitcoin and for many other cryptocurrencies since their inception), the timespan is very much limited to a maximum of 10 years (bitcoin) - with the observations during the early years that are quite meaningless because of the very small volumes. Thus, researchers can hardly derive any final conclusion and further analysis is needed to properly appreciate bitcoin and cryptocurrencies' role; in particular if one considers the 2017 boom/burst evolution.

As far as the regulators are concerned, our analysis suggests two challenges: 1) it is imperative to expand knowledge of this innovative tool as fast as possible in order to evaluate whether any additional regulation is needed and, if this is the case, what kind of rules should be implemented. In fact, if on the one hand too strict a regulation can constrain the expansion of a financial tool that can be an efficient payment tool (if we follow Nakamoto (2008) argument) and an interesting asset to invest in, the lack of it (or a very loose one) can put at risk the savings of many 
people that can be attracted by the idea of easily obtaining high returns in a very short time without perceiving the real risk incurred in the investment; 2) it is important for regulators to act rapidly and effectively in any decision about bitcoin. Bitcoin and cryptocurrencies in general evolve at a speed that is different to what we are used to (e.g. bitcoin was considered to be an inefficient asset till two years ago (Urquhart, 2016) but recently academics changed their mind considering it an efficient one (Wei, 2018) that can be used in portfolio diversification as suggested by our work). The same applies to their popularity. This implies that regulators have to be able to deal with financial tools that evolve very rapidly and become popular even faster.

\section{Conclusions}

Bitcoin is arguably one of the most important financial innovations in recent times. It has drawn an increasing number of critics and supporters, yet its rise has been exceptional since its inception in the early 2009 when one bitcoin sold for less than a $\$ 0.01$ and continued to climb the highs of almost 20,000USD by the fourth quarter of 2017 . There is now a rising body of academic literature attempting to explain various value drivers that have contributed to this, such as the genuine transaction demand, speculation, and the in-built deflationary characteristics of bitcoin. There's also a growing body of literature attempting to analyse its other financial characteristics, such as the particularly high volatility, correlations with other more traditional assets and any potential roles that it could play in the financial and investment markets. However, the research remains quite scarce and draws conclusions from the U.S. perspective. There is no previous research that covers the role of bitcoin in portfolios of European and Chinese assets.

Our results show some common themes between the inclusion of bitcoin in a portfolio of U.S., European and Chinese assets: it generates benefits in terms of improvement of the returns, but it tends also to increase volatility. However, portfolio performance in terms of Risk-Return ratio, 
Sortino ratio and Omega ratio tend to improve. The benefit of bitcoin inclusion is linked to the increase in the return that compensate for the increase in the risk of the portfolio. Interestingly, the positive effect of adding bitcoin to a portfolio is mainly linked to the period before the end of 2013, with marginal benefits thereafter. This finding applies to naïve and long portfolios. Where unleveraged shorting is allowed, effects on the risk-return ratio are more marginal throughout the sample period. The reason behind the relevant role played by bitcoin is linked to the increase in bitcoin in 2013. In fact, after February 2014 bitcoin presents quite a high volatility but with less pronounced increase in its value.

An additional outcome of this research relates to the (under)performance of the portfolios where shorting is present compared to the long-only portfolios and especially the naïve portfolio. This finding is in line with DeMiguel et al. (2007) who show that naïve portfolios often perform better than optimised portfolios in general. However, this does not necessarily explain the entire story since it might be also partially due to the infrequent semi-annual re-balancing we implemented.

However, this research opens to further areas of study. A first aspect that asks for additional investigation is a detailed analysis of the events at the end of 2013 beginning 2014 that affected the performance of the inclusion of Bitcoin. This is an interesting area since a clearer understanding of the role played by bitcoin's high volatility and its increase in value can allow for a better management of bitcoin as an asset. Secondly, this is the first research to investigate the role of bitcoin in China and Europe and one of the few that explore the role in U.S. In actual fact, we do not find any major differences in the role of bitcoin in the contexts under investigation. However, it can be interesting to explore bitcoin's role in portfolios containing fewer liquid assets (such as bonds and shares listed in minor markets). Thirdly, at the beginning of 2017 bitcoin represented the bulk of the total market capitalisation of all tradeable cryptocurrencies. By September 2017, this proportion has fallen ${ }^{9}$ to under $50 \%(60 \mathrm{bn} / 130 \mathrm{bn})$, mainly due to the faster expansion of alternative

\footnotetext{
${ }^{9}$ Source: https://coinmarketcap.com/ (accessed 23 September 2017)
} 
cryptocurrencies (e.g. Ether, Litecoin, etc.). This has given rise to a variety of theoretical cryptoindices such as the CRIX ${ }^{10}$ and the WorldCoinIndex ${ }^{11}$. Future research should seek to explore the effects of such indices on optimal portfolios for a more comprehensive analysis. An additional area of analysis is to explore the long-term effect of the high increase in value of bitcoin in 2017 and the subsequent decrease and high volatility, similarly to the work by Platanakis and Urquhart (2018): our result suggests that until 2016 the benefit of including bitcoin was mainly due to the improved returns that compensate for the increase in $\mathrm{C}-\mathrm{VaR}$. Considering the stellar increase in bitcoin value, this effect can hold in 2017 as well. However, the 2017 "bitcoin bubble" exploded at least partially at the beginning of 2018 with a downward trend in the returns while maintaining a high volatility of its value. Thus, further analysis is needed in order to appreciate the real "2017" bitcoin long term effect on a portfolio of assets. Further, we do not explore in detail the correlation between bitcoin and other assets/currencies (along the lines of the works by Baumöhl (2018) and Burnie (2018) and we do not touch the very relevant topic of spillovers (e.g. the seminal work by Guesmi et al., (2018). In fact, these are relevant areas to be explored when it turns to manage portfolios of assets that include bitcoin or other cryptocurrencies. Finally, a further area of research is linked to the possibility of using bitcoin to hedge forex and commodities risk (Bouri, Molnár, et al., 2017).

Notwithstanding the limitations, our study indicates that bitcoin is an emerging relevant asset class and it might play a more relevant role in portfolio diversification strategies in U.S., Europe and China than has heretofore been acknowledged.

\footnotetext{
${ }^{10} \mathrm{http}: / /$ crix.hu-berlin.de/

${ }^{11} \mathrm{https}$ //www.worldcoinindex.com/
} 


\section{References}

Acerbi, C., \& Tasche, D. (2002). Expected Shortfall: A Natural Coherent Alternative to Value at Risk. Economic Notes by Banca Monte Dei Paschi Di Siena SpA, 31(2), 379-388.

Adrianto, Y., \& Diputra, Y. (2017). The Effect of Cryptocurrency on Investment Portofolio Effectiveness. Journal of Finance and Accounting, 5(6), 229-238.

Alexander, G. J., \& Baptista, A. M. (2004). A Comparison of VaR and CVaR Constraints on Portfolio Selection with the Mean-Variance Model. Management Science, 50(9), 1261-1273.

Allowey, T. (2011). Virtual Money, from Real Central Bank Mistrust. Financial Times.

Artzner, P., Delbaen, F., Eber, J., \& Heath, D. (1999). Coherent Measures of Risk. Mathematical Finance, 9(3), 203-228.

Barnes, T., \& Burnie, D. (1990). Corporate Bonds, Term Structure Expecation and Optimal Portolios: The Canadian Experience. Journal of Business Finance \& Accounting, 17(3), 411420.

Baumöhl, E. (2018). Are cryptocurrencies connected to forex? A quantile crossspectral approach. In Cryptocurrency Research Conference 2018. Cambridge.

Bernardo, A. E. ., \& Ledoit, O. (2000). Gain, Loss, and Asset Pricing. Journal of Political Economy, $108(1), 144-172$.

Bhattacharya, S., \& Ritter, J. R. (1983). Innovation and Communication: Signalling with Partial Disclosure. Review of Economic Studies, 50(2), 331-346.

Böhme, R., Nicolas, C., Edelman, B., \& Moore, T. (2015). Bitcoin: Economics, Technology, and Governance. Journal of Economic Perspectives, 9(2), 213-238.

Bouri, E., Molnár, P., Azzi, G., Roubaud, D., \& Hagfors, L. I. (2017). On the hedge and safe haven properties of Bitcoin: Is it really more than a diversifier? Finance Research Letters, 20, 192198. 
Bouri, E., Naji, J., Molnár, P., \& Roubaud, D. (2017). Bitcoin for Energy Commodities before and after the December 2013 Crash: Diversifier, Hedge or Safe Haven? Applied Economics, 49(50), $5063-5073$.

Brauneis, A., \& Mestel, R. (2018). Price Discovery of Cryptocurrencies: Bitcoin and Beyond. Economic Letters, 165, 58-61.

Brière, M., Oosterlinck, K., \& Szafarz, A. (2015). Virtual Currency, Tangible Return: Portfolio Diversification with Bitcoin. Journal of Asset Management, 16(6), 365-373.

Brunnermeier, M. K. (2016). Bubbles. In G. Jones (Ed.), Banking Crises. London: Palgrave Macmillan.

Burnie, A. (2018). Exploring the Interconnectedness of Cryptocurrencies using Correlation Networks. In Cryptocurrency Research Conference 2018. Cambridge, UK.

Carrick, J. (2016). Bitcoin as a Complement to Emerging Market Currencies. Emerging Markets Finance \& Trade, 52(10), 2321-2334.

Cheah, E., \& Fry, J. (2015). Speculative bubbles in Bitcoin markets? An empirical investigation into the fundamental value of Bitcoin. Economics Letters, 130, 32-36.

Ciaian, P., Rajcaniova, M., \& Kancs, D. (2015). The economics of BitCoin price formation. Applied Economics, 48(19), 1799-1815.

Cipolla, C. M. (1994). Uomini Duri. In C. M. Cipolla (Ed.), Tre Storie Extravaganti. Bologna: Il Mulino.

Corbet, S., Lucey, B., Urquhart, A., \& Yarovaya, L. (2018). Cryptocurrencies as a Financial Asset: A systematic analysis. International Review of Financial Analysis, Forthcomin. http://doi.org/10.1016/j.irfa.2018.09.003

Corbet, S., Meegan, A., Larkin, C., Lucey, B., \& Yarovaya, L. (2018). Exploring the Dynamic Relationships between Cryptocurrencies and Other Financial Assets. Economic Letters, 165, 28-34. 
de Soto, J. (1995). A critical analysis of central banks and fractional-reserve free banking from the Austrian school perspective. The Review of Austrian Economics, 8(2), 25-38.

DeMiguel, V., Garlappi, L., \& Uppal, R. (2007). Optimal Versus Naive Diversification: How Inefficient is the 1/N Portfolio Strategy? Review of Financial Studies, 22(5), 1915-1953. Dyhrberg, A. H. (2016a). Bitcoin, Gold and Dollar - A GARCH Volatility Analayis. Finance Research Letters, 16, 85-92.

Dyhrberg, A. H. (2016b). Hedging Capabilities of Bitcoin. Is It the Virtual Gold. Finance Research Letters, 16, 139-144.

Dyhrberg, A. H., Foley, S., \& Svec, J. (2018). How Investible is Bitcoin? Analyzing the Liquidity and Transaction Costs of Bitcoin Markets. Economic Letters, 171, 140-143.

Eisl, A., Gasser, S. M., \& Weinmayer, K. (2015). Caveat Emptor: Does Bitcoin Improve Portfolio Diversification?

Fox, J. (2014). What's That You're Calling Bubble? Harvard Business Review.

Fry, J. (2018). Booms, Busts and Heavy-Tails: The Story of Bitcoin and Cryptocurrency Markets? Economic Letters, 17, 225-229.

Galai, D., \& Geske, R. (1984). Option performance measurement. Journal of Portfolio Management, $10(3), 42-46$.

Garcia, D., Tessone, C., Mavrodiev, P., \& Perony, N. (2014). The digital traces of bubbles: feedback cycles between socio-economic signals in the Bitcoin economy. Journal of The Royal Society Interface, 11(99), 623-623.

Glaser, F., Zimmermann, K., Haferkorn, M., Christian Weber, M., \& Siering, M. (2014). BitcoinAsset or Currency? Revealing Users' Hidden Intentions. In Proceedings of the 22nd European Conference on Information Systems. Tel Aviv.

Guesmi, K., Saadi, S., Abid, I., \& Ftiti, Z. (2018). Portfolio Diversification with Visrtual Currency: Evidence from Bitcoin. International Review of Financial Analysis, Forthcoming. 
http://doi.org/10.1016/j.irfa.2018.03.004

Hamao, Y., Masulis, R. W., \& Ng, V. (1990). Correlations in Price Changes and Volatility across International Stock Markets. Review of Financial Studies, 3 Issue(2), 281-307.

Harvey, C. (2017). Cryptofinance.

Johnson, R., \& Soenen, L. (2004). The US Stock Market and the International Value of the US dollar. Journal of Economics \& Business, 56(6), 469-481.

Kaminska, I. (2017). The HODL. Financial Times.

Karalevicius, V., Degrande, N., \& De Weerdt, J. (2018). Using Sentiment Analysis to Predict Interday Bitcoin Price Movements. The Journal of Risk Finance, 19(2), 127-136.

Katsiampa, P. (2017). Volatility estimation for Bitcoin: A comparison of GARCH models. Economic Letters, 158, 3-6.

Kearney, C., \& Daly, K. (1998). The causes of stock market volatility in Australia. Applied Financial Economics, 8(6), 597-605.

Keating, C., \& Shadwick, W. (2002). A Universal Performance Measure. Journal of Performance Measurement, 6(3), 59-84.

Keynes, J. M. (1936). The General Theory of Employment, Interest, and Money. Basingstoke, Hampshire: Palgrave Macmillan.

Koutmos, D. (2018). Bitcoin Returns and Transaction Activity. Economic Letters, 167, 81-85.

Kristoufek, L. (2015). What Are the Main Drivers of the Bitcoin Price? Evidence from Wavelet Coherence Analysis. PLOS ONE, 10(4).

Makin, J. (1978). Portfolio theory and the Problem of Foreign Exchange Risk. Journal of Finance, $33(2), 517-534$.

Markowitz, H. M. (1952). Portfolio Selection. The Journal of Finance, 7(1), 77-91.

Markowitz, H. M. (1976). Markowitz Revisited. Financial Analyst Journal, Sept. 76(47-52).

Meyer, G. (2017). Bitcoin futures broker to allow negative bets. Financial Times. 
Nadarajah, S., \& Chu, J. (2017). On the inefficiency of Bitcoin. Economics Letters, 150, 6-9.

Nakamoto, S. (2008). Bitcoin: A peer-to-peer electronic cash system. Retrieved from https://bitcoin.org/en/bitcoin-paper

Narayanan, A., Bonneau, J., Felten, E., Miller, A., \& Goldfeder, S. (2017). Bitcoin and

Cryptocurrencies Technology (1st ed.). Princeton NJ: Princeton University Press.

Phillip, A., Chan, J. S. K., \& Peiris, S. (2018). A New Look at Cryptocurrencies. Economic Letters, $163,6-9$.

Platanakis, E., \& Urquhart, A. (2018). Should Investors Include Bitcoin in Their Portfolios? A Portfolio Theory Approach. In Cambridge Cryptocurrency Research Conference (pp. 1-26).

Pojarliev, M., \& Levich, R. (2011). Are All Currency Managers Equal? Journal of Portfolio Management, 37(4), 42-53.

Polasik, M., Piotrowska, A., Wisniewski, T. P., Kotkowski, R., \& Lightfoot, G. (2015). Price Fluctuations and the Use of Bitcoin: An Empirical Inquiry. International Journal of Electronic Commerce, 20(1), 9-49.

Pyun, C. S., Lee, S. Y., \& Nam, K. (2000). Volatility and information flows in emerging equity market A case of the Korean Stock Exchange. International Review of Financial Analysis, 9(4), $405-431$.

Ruban, O., \& Melas, D. (2011). Constructing Risk Parity Portfolios: Rebalance, Leverage, or Both? Journal of Investing, 20(1), 99-107.

Sharpe, W. (1963). A Simplified Model for Portfolio Analysis. Management Science, 9(2), 277-293. Sharpe, W. (1964). Capital Asset Prices - A Theory of Market Equilibrium Under Conditions of Risk. Journal of Finance, 19(3), 425-442.

Silvapulle, P., \& Granger, C. W. (2001). Large returns, conditional correlation and portfolio diversification: a value-at-risk approach. Quantitative Finance, 1(5), 542-551.

Smetters, K., \& Zhang, X. (2014). A Sharper Ratio: A General Measure of Correctly Ranking Non- 
Normal Investment Risks.

Sortino, F. A., \& van der Meer, R. (1991). Downside Risk. Journal of Portfolio Management, 17, 27-31.

Stein, D. M., Siegel, A. F., Narasimhan, P., \& Appeadu, C. E. (2000). Diversification in the Presence of Taxes. Journal of Portfolio Management., 27(1), 61-71.

Topaloglou, N., Vladimirou, H., \& Zenios, S. (2002). CVaR models with selective hedging for international asset allocation. Journal of Banking \& Finance, 26(7), 1535-1562.

Treynor, J. L., \& Black, F. (1973). How to Use Security Analysis to Improve Portfolio Selection. Journal of Business, 46(1), 66-86.

Urquhart, A. (2016). The inefficiency of Bitcoin. Economics Letters, 148, 80-82.

Urquhart, A. (2017). Price Clustering in Bitcoin. Economic Letters, 159, 145-148.

Van Vliet, B. (2018). An Alternative Model of Metcalfe's Law for Valuing Bitcoin. Economic Letters, $165,70-72$.

Wei, W. C. (2018). Liquidity and Market Efficiency in Cryptocurrencies. Economic Letters, 168, 2124.

Wisniewski, T. P., \& Moro, A. (2014). When EU Leaders Speak, the Markets Listen. European Accounting Review, 23(4), 519-551.

Wu, C. Y., \& Pandey, V. K. (2014). The Value of Bitcoin in Enhancing the Efficiency of an Investor's Portfolio. Journal of Financial Planning., 27(9), 44-52. 
Table 1 - Asset Classes Included in the Analysis

\begin{tabular}{|c|c|c|c|}
\hline & Name & Mnemonic & Asset Class \\
\hline 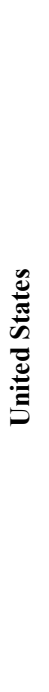 & $\begin{array}{l}\text { BTC-USD-Index } \\
\text { S\&P U.S. TREASURY BILL INDEX } \\
\text { S\&P U.S. TREASURY BOND INDEX } \\
\text { DOW JONES EQUAL WEIGHTS U.S. ISSUED CORPORATE BONDS } \\
\text { S\&P WCI GOLD (ER) } \\
\text { S\&P } 100 \\
\text { S\&P } 500 \\
\text { S\&P } 600 \\
\text { S\&P WCI } \\
\text { DOW JONES U.S. REAL EASTATE INDEX } \\
\text { Global hedge fund index } \\
\text { Dow Jones FXCM Dollar Index }\end{array}$ & $\begin{array}{l}\text { btcusd } \\
\text { billus } \\
\text { condus } \\
\text { corpus } \\
\text { gold } \\
\text { sp100 } \\
\text { sp500 } \\
\text { spsml } \\
\text { wcig } \\
\text { resus } \\
\text { hfrx } \\
\text { usdollar }\end{array}$ & $\begin{array}{l}\text { Cryptocurrency } \\
\text { Money Market } \\
\text { Fixed-income } \\
\text { Fixed-income } \\
\text { Gold ETF } \\
\text { Equity (large } \\
\text { cap) } \\
\text { Equity (mid cap) } \\
\text { Equity (small } \\
\text { cap) } \\
\text { Commodities } \\
\text { Real Estate } \\
\text { Alternative } \\
\text { Currency }\end{array}$ \\
\hline & $\begin{array}{l}\text { BTC } \\
\text { S\&P Pan-Europe Developed Sovereign Bond Index } \\
\text { S\&P Eurozone Investment Grade Corporate Bond Index } \\
\text { S\&P WCI GOLD (ER) } \\
\text { S\&P EUROPE } 350 \\
\text { S\&P WCI Europe } \\
\text { Dow Jones Europe Select Real Estate Securities Index } \\
\text { Global hedge fund index } \\
\text { S\&P EURO Futures Index Spot }\end{array}$ & $\begin{array}{l}\text { btceur } \\
\text { condeu } \\
\text { corpeu } \\
\text { gold } \\
\text { sp350eu } \\
\text { wcie } \\
\text { reseu } \\
\text { hfrx } \\
\text { speuf }\end{array}$ & $\begin{array}{l}\text { Cryptocurrency } \\
\text { Fixed-income } \\
\text { Fixed-income } \\
\text { Gold ETF } \\
\text { Equity } \\
\text { Commodities } \\
\text { Real Estate } \\
\text { Alternative } \\
\text { Currency }\end{array}$ \\
\hline 离 & $\begin{array}{l}\text { BTC-CNY-Index } \\
\text { S\&P CHINA GOVERNMENT BILL INDEX } \\
\text { S\&P CHINA SOVEREIGN BOND INDEX } \\
\text { S\&P CHINA CORPORATE BOND INDEX } \\
\text { S\&P WCI GOLD (ER) } \\
\text { S\&P CHINA A } 100 \text { INDEX (RMB) } \\
\text { S\&P CHINA A } 200 \text { INDEX (RMB) } \\
\text { S\&P CHINA A SMALLCAP INDEX (RMB) } \\
\text { S\&P WCI ASIA } \\
\text { Guggenheim China Real Estate ETF (TAO) } \\
\text { Global hedge fund index } \\
\text { USDCNY Exchange rate (holding USD as investment) }\end{array}$ & $\begin{array}{l}\text { btceny } \\
\text { billen } \\
\text { conden } \\
\text { corpen } \\
\text { gold } \\
\text { spc100 } \\
\text { spc200 } \\
\text { spcsml } \\
\text { wcia } \\
\text { tao } \\
\text { hfrx } \\
\text { usdeny }\end{array}$ & $\begin{array}{l}\text { Cryptocurrency } \\
\text { Money Market } \\
\text { Fixed-income } \\
\text { Fixed-income } \\
\text { Gold ETF } \\
\text { Equity (large } \\
\text { cap) } \\
\text { Equity (mid cap) } \\
\text { Equity (small } \\
\text { cap) } \\
\text { Commodities } \\
\text { Real Estate } \\
\text { Alternative } \\
\text { Currency }\end{array}$ \\
\hline
\end{tabular}


Table 2 A Descriptive Statistics U.S. Assets

\begin{tabular}{|c|c|c|c|c|c|c|c|c|c|c|c|c|}
\hline \multicolumn{13}{|c|}{ Descriptive Statistics of excess monthly returns } \\
\hline & btcusd & billus & condus & corpus & gold & sp100 & $\mathrm{sp} 500$ & spsml & wcig & resus & hfrx & usdollar \\
\hline Min & $-55.99 \%$ & $-0.05 \%$ & $-2.67 \%$ & $-5.12 \%$ & $-14.49 \%$ & $-12.32 \%$ & $-11.64 \%$ & $-12.21 \%$ & $-20.40 \%$ & $-16.48 \%$ & $-4.17 \%$ & $-3.93 \%$ \\
\hline Max & $208.31 \%$ & $0.07 \%$ & $2.31 \%$ & $3.86 \%$ & $12.19 \%$ & $11.77 \%$ & $10.55 \%$ & $17.56 \%$ & $19.26 \%$ & $13.34 \%$ & $2.71 \%$ & $3.90 \%$ \\
\hline Mean & $12.84 \%$ & $0.00 \%$ & $0.08 \%$ & $0.35 \%$ & $-0.35 \%$ & $1.25 \%$ & $1.10 \%$ & $1.28 \%$ & $-0.84 \%$ & $0.58 \%$ & $0.14 \%$ & $0.34 \%$ \\
\hline Median & $6.51 \%$ & $-0.01 \%$ & $0.10 \%$ & $0.43 \%$ & $-0.22 \%$ & $1.58 \%$ & $1.30 \%$ & $1.43 \%$ & $-0.40 \%$ & $1.03 \%$ & $0.31 \%$ & $0.27 \%$ \\
\hline Skewness & 2.38 & 1.11 & -0.33 & -0.55 & -0.06 & -0.58 & -0.50 & 0.03 & -0.22 & -0.45 & -0.84 & 0.06 \\
\hline Kurtosis & 7.99 & 1.76 & 1.09 & 1.04 & 0.05 & 1.25 & 1.07 & 0.68 & 0.26 & 0.52 & 0.91 & -0.45 \\
\hline St.Dev. & $34.90 \%$ & $0.02 \%$ & $0.76 \%$ & $1.34 \%$ & $4.54 \%$ & $3.07 \%$ & $3.05 \%$ & $4.14 \%$ & $6.79 \%$ & $4.05 \%$ & $1.12 \%$ & $1.34 \%$ \\
\hline VaR & $24.63 \%$ & $0.02 \%$ & $1.16 \%$ & $2.28 \%$ & $7.81 \%$ & $4.53 \%$ & $4.44 \%$ & $5.45 \%$ & $13.17 \%$ & $6.86 \%$ & $2.04 \%$ & $1.71 \%$ \\
\hline C-VaR & $32.90 \%$ & $0.03 \%$ & $1.70 \%$ & $3.01 \%$ & $9.91 \%$ & $6.49 \%$ & $6.49 \%$ & $7.60 \%$ & $16.29 \%$ & $8.74 \%$ & $2.76 \%$ & $2.24 \%$ \\
\hline Sharpe (C-VaR) & 0.39 & 0.00 & 0.04 & 0.11 & -0.04 & 0.19 & 0.17 & 0.17 & -0.05 & 0.07 & 0.05 & 0.15 \\
\hline
\end{tabular}


Table 2B Descriptive Statistics European Assets

\begin{tabular}{|c|c|c|c|c|c|c|c|c|c|}
\hline \multicolumn{10}{|c|}{ Descriptive Statistics } \\
\hline & btceur & condeu & corpeu & gold & sp350eu & wcie & reseu & hfrx & speuf \\
\hline Min & $-54.15 \%$ & $-3.99 \%$ & $-2.83 \%$ & $-14.88 \%$ & $-16.18 \%$ & $-23.55 \%$ & $-18.11 \%$ & $-4.57 \%$ & $-8.71 \%$ \\
\hline Max & $190.69 \%$ & $2.66 \%$ & $1.46 \%$ & $11.79 \%$ & $11.83 \%$ & $20.47 \%$ & $12.02 \%$ & $2.32 \%$ & $7.14 \%$ \\
\hline Mean & $12.76 \%$ & $0.00 \%$ & $-0.07 \%$ & $-0.75 \%$ & $0.51 \%$ & $-1.24 \%$ & $0.19 \%$ & $-0.26 \%$ & $-0.67 \%$ \\
\hline Median & $6.43 \%$ & $0.18 \%$ & $0.07 \%$ & $-0.62 \%$ & $0.69 \%$ & $-0.66 \%$ & $0.52 \%$ & $-0.08 \%$ & $-0.59 \%$ \\
\hline Skewness & 2.22 & -0.85 & -0.83 & -0.06 & -0.51 & -0.25 & -0.39 & -0.84 & -0.27 \\
\hline Kurtosis & 7.02 & 0.90 & 0.67 & 0.05 & 0.85 & 0.38 & 0.11 & 0.91 & 0.58 \\
\hline St.Dev. & $33.82 \%$ & $1.13 \%$ & $0.66 \%$ & $4.54 \%$ & $3.98 \%$ & $7.33 \%$ & $4.74 \%$ & $1.12 \%$ & $2.31 \%$ \\
\hline VaR & $22.90 \%$ & $2.28 \%$ & $1.40 \%$ & $8.21 \%$ & $6.85 \%$ & $14.94 \%$ & $7.99 \%$ & $2.43 \%$ & $4.43 \%$ \\
\hline C-VaR & $32.93 \%$ & $2.94 \%$ & $1.75 \%$ & $10.31 \%$ & $9.32 \%$ & $18.22 \%$ & $10.50 \%$ & $3.15 \%$ & $6.00 \%$ \\
\hline Sharpe (C-VaR) & 0.39 & 0.00 & -0.04 & -0.07 & 0.05 & -0.07 & 0.02 & -0.08 & -0.11 \\
\hline
\end{tabular}


Table 2C Descriptive Statistics Chinese Assets

Descriptive Statistics of excess monthly returns

\begin{tabular}{lrrrrrrrrrrrr} 
& \multicolumn{1}{c}{ btccny } & \multicolumn{1}{c}{ billcn } & condcn & corpcn & \multicolumn{1}{c}{ gold } & spc100 & spc200 & spcsml & wcia & tao & hfrx & usdcny \\
\hline \hline Min & $-56.21 \%$ & $-1.79 \%$ & $-3.47 \%$ & $-2.13 \%$ & $-14.70 \%$ & $-33.33 \%$ & $-47.12 \%$ & $-53.94 \%$ & $-11.89 \%$ & $-22.39 \%$ & $-4.39 \%$ & $-1.84 \%$ \\
Max & $208.10 \%$ & $1.74 \%$ & $3.19 \%$ & $2.95 \%$ & $11.97 \%$ & $33.12 \%$ & $28.94 \%$ & $35.67 \%$ & $13.65 \%$ & $18.02 \%$ & $2.50 \%$ & $3.02 \%$ \\
Mean & $12.63 \%$ & $0.00 \%$ & $0.09 \%$ & $0.20 \%$ & $-0.57 \%$ & $0.61 \%$ & $0.61 \%$ & $1.01 \%$ & $-0.73 \%$ & $0.61 \%$ & $-0.08 \%$ & $-0.07 \%$ \\
Median & $6.29 \%$ & $-0.03 \%$ & $0.12 \%$ & $0.22 \%$ & $-0.44 \%$ & $0.57 \%$ & $1.25 \%$ & $1.32 \%$ & $-0.91 \%$ & $1.22 \%$ & $0.10 \%$ & $-0.23 \%$ \\
Skewness & 2.38 & -0.17 & -0.32 & -0.06 & -0.06 & 0.31 & -0.97 & -0.93 & 0.31 & -0.46 & -0.84 & 1.01 \\
Kurtosis & 7.99 & 6.26 & 1.01 & 1.24 & 0.05 & 2.86 & 3.54 & 4.50 & 0.25 & 0.54 & 0.91 & 1.08 \\
St.Dev. & $34.90 \%$ & $0.32 \%$ & $0.88 \%$ & $0.73 \%$ & $4.54 \%$ & $7.77 \%$ & $9.00 \%$ & $9.90 \%$ & $4.07 \%$ & $6.44 \%$ & $1.12 \%$ & $0.83 \%$ \\
VaR & $24.85 \%$ & $0.34 \%$ & $1.40 \%$ & $1.15 \%$ & $8.03 \%$ & $11.59 \%$ & $15.40 \%$ & $15.52 \%$ & $7.36 \%$ & $9.67 \%$ & $2.25 \%$ & $1.18 \%$ \\
C-VaR & $33.11 \%$ & $0.73 \%$ & $1.99 \%$ & $1.52 \%$ & $10.13 \%$ & $17.59 \%$ & $24.61 \%$ & $26.72 \%$ & $8.50 \%$ & $14.75 \%$ & $2.97 \%$ & $1.34 \%$ \\
Sharpe (C-VaR) & 0.38 & 0.00 & 0.04 & 0.13 & -0.06 & 0.03 & 0.02 & 0.04 & -0.09 & 0.04 & -0.03 & -0.05 \\
\hline \hline
\end{tabular}


Figure 1A U.S. Assets Distributions of Excess Returns

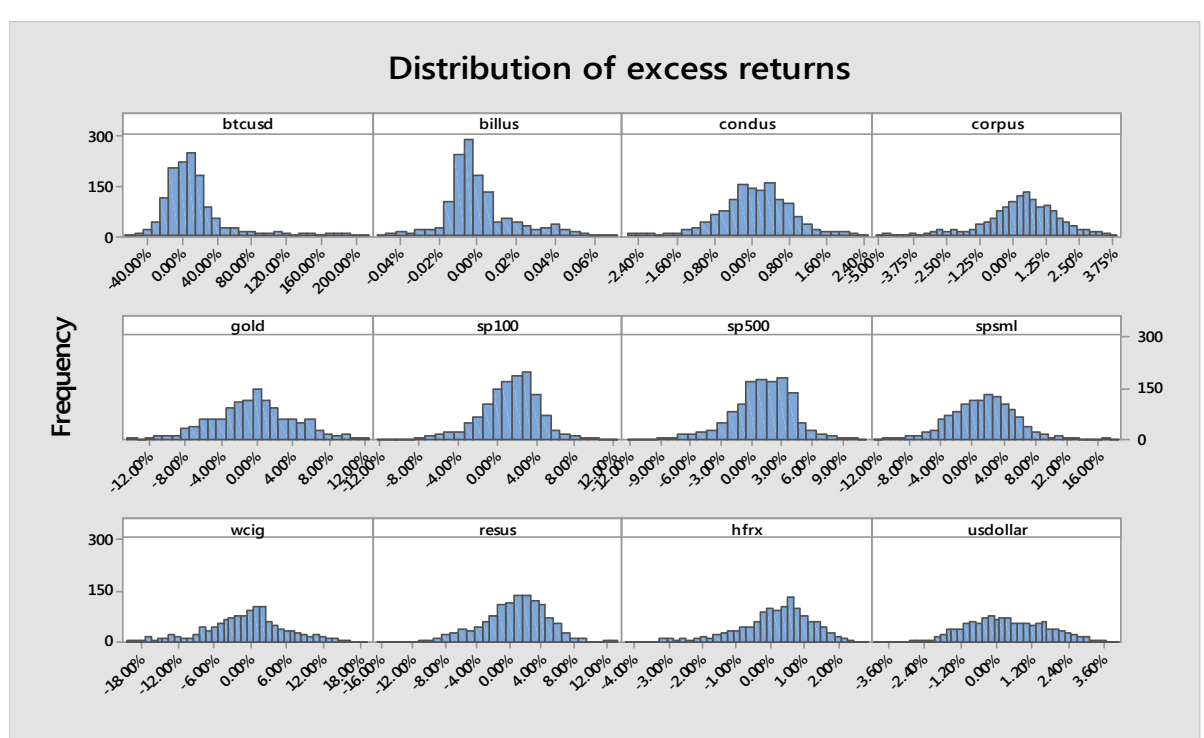


Figure 1B European Assets Distributions of Excess Returns

Distribution of excess returns

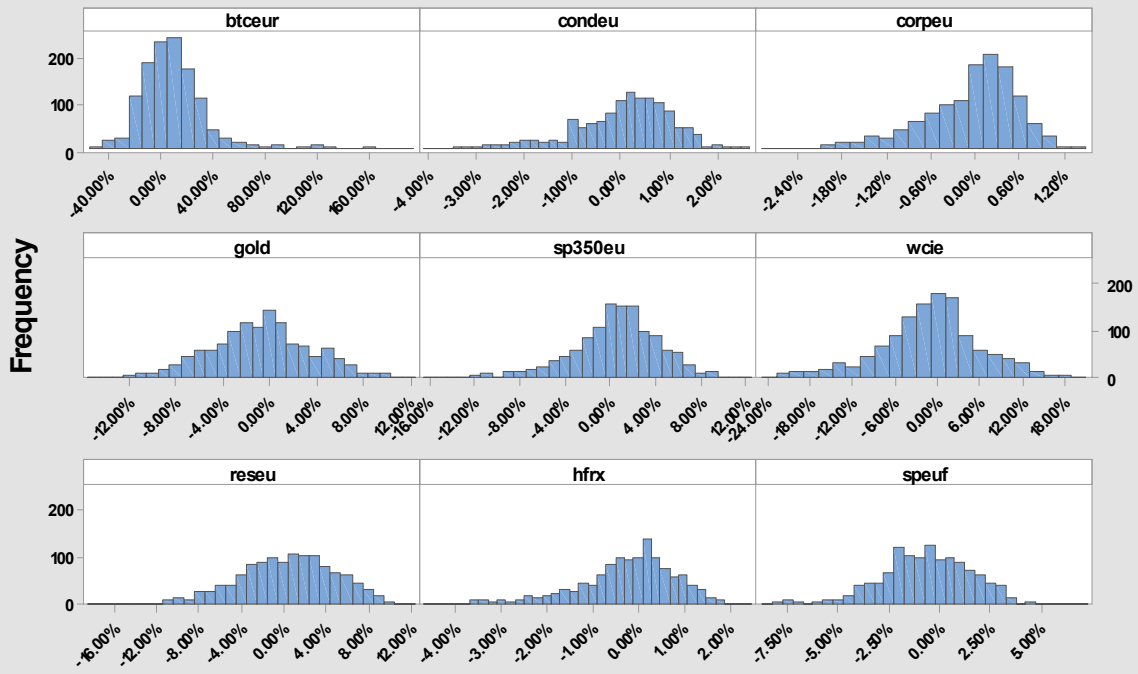

45 
Figure 1C Chinese Assets Distributions of Excess Returns

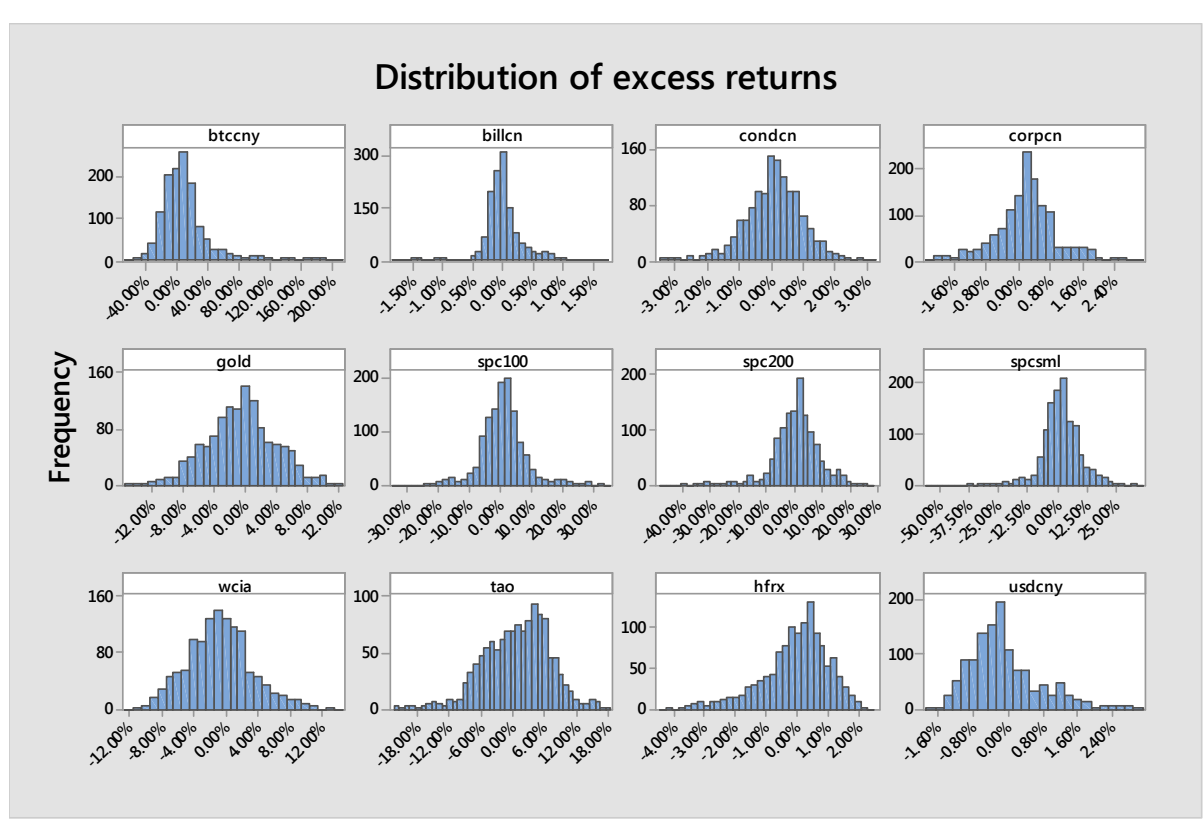


Table 3 A Correlation Matrix U.S. Assets

Correlation Matrix - Coefficients (P-Values)

\begin{tabular}{|c|c|c|c|c|c|c|c|c|c|c|c|}
\hline & btcusd & billus & condus & corpus & gold & sp100 & sp500 & spsml & wcig & resus & hfrx \\
\hline billus & $-0.087 * * *$ & & & & & & & & & & \\
\hline condus & $-0.051 *$ & $0.245^{* * *}$ & & & & & & & & & \\
\hline corpus & 0.009 & $0.230 * * *$ & $0.772 * * *$ & & & & & & & & \\
\hline gold & $-0.183^{* * *}$ & $0.325^{* * *}$ & $0.424 * * *$ & $0.364^{* * *}$ & & & & & & & \\
\hline sp100 & $0.264 * * *$ & $-0.110 * * *$ & $-0.322 * * *$ & 0.028 & $-0.099 * * *$ & & & & & & \\
\hline sp500 & $0.244^{* * *}$ & $-0.097 * * *$ & $-0.316^{* * *}$ & 0.042 & $-0.082 * * *$ & $0.990^{* * *}$ & & & & & \\
\hline spsml & $0.150 * * *$ & $-0.057^{* *}$ & $-0.407^{* * *}$ & $-0.081 * * *$ & $-0.101^{* * *}$ & $0.801^{* * *}$ & $0.850 * * *$ & & & & \\
\hline wcig & $0.063^{* *}$ & $0.273^{* * *}$ & $-0.306 * * *$ & -0.030 & $0.117^{* * *}$ & $0.354 * * *$ & $0.361 * * *$ & $0.387^{* * *}$ & & & \\
\hline resus & 0.006 & $0.086 * * *$ & $0.335^{* * *}$ & $0.586 * * *$ & $0.137^{* * *}$ & $0.522 * * *$ & $0.564^{* * *}$ & $0.459 * * *$ & 0.007 & & \\
\hline hfrx & $0.187^{* * *}$ & 0.035 & $-0.289 * * *$ & $0.078^{* *}$ & $-0.092 * * *$ & $0.763^{* * *}$ & $0.802 * * *$ & $0.760 * * *$ & $0.441^{* * *}$ & $0.440 * * *$ & \\
\hline usdollar & $0.058^{* *}$ & $-0.257 * * *$ & $-0.170 * * *$ & $-0.233 * * *$ & $-0.454 * * *$ & -0.027 & -0.027 & 0.014 & $-0.338^{* * *}$ & $-0.059 * *$ & 0.044 \\
\hline
\end{tabular}


Table 3B Correlation Matrix European Assets

Correlation Matrix - Coefficients (P-Values)

\begin{tabular}{|c|c|c|c|c|c|c|c|c|}
\hline & btceur & condeu & corpeu & gold & sp350eu & wcie & reseu & hfrx \\
\hline condeu & 0.041 & & & & & & & \\
\hline corpeu & $0.127^{* * *}$ & $0.793^{* * *}$ & & & & & & \\
\hline gold & $-0.191 * * *$ & $0.213^{* * *}$ & $0.144 * * *$ & & & & & \\
\hline sp350eu & $0.145^{* * *}$ & $0.160 * * *$ & $0.394 * * *$ & $-0.083 * * *$ & & & & \\
\hline wcie & $0.060 * *$ & $-0.254 * * *$ & 0.007 & $0.087^{* * *}$ & $0.291^{* * *}$ & & & \\
\hline reseu & 0.021 & $0.298^{* * *}$ & $0.473^{* * *}$ & $0.074^{* * *}$ & $0.654 * * *$ & $0.216^{* * *}$ & & \\
\hline hfrx & $0.215^{* * *}$ & 0.04 & $0.308^{* * *}$ & $-0.092 * * *$ & $0.776^{* * *}$ & $0.445^{* * *}$ & $0.507 * * *$ & \\
\hline speuf & -0.090 & $-0.214^{* * *}$ & $-0.192 * * *$ & $0.302 * * *$ & $-0.316^{* * *}$ & $0.239 * * *$ & $0.197 * * *$ & $-0.100 * * *$ \\
\hline
\end{tabular}


Table 3C Correlation Matrix Chinese Assets

Correlation Matrix - Coefficients (P-Values)

\begin{tabular}{|c|c|c|c|c|c|c|c|c|c|c|c|}
\hline & btccny & billcn & conden & corpcn & gold & spc100 & spc200 & spcsml & wcia & tao & hfrx \\
\hline billcn & $-0.357 * * *$ & & & & & & & & & & \\
\hline conden & $-0.254^{* * *}$ & $0.619 * * *$ & & & & & & & & & \\
\hline corpen & $-0.250 * * *$ & $0.683 * * *$ & $0.863 * * *$ & & & & & & & & \\
\hline gold & $-0.183 * * *$ & $0.085^{* * *}$ & $0.049^{*}$ & 0.009 & & & & & & & \\
\hline spc100 & $-0.080 * * *$ & $0.051^{*}$ & $-0.060 * *$ & $-0.121 * * *$ & 0.038 & & & & & & \\
\hline spc200 & $-0.057^{* *}$ & $0.193^{* * *}$ & -0.045 & -0.028 & -0.015 & $0.845^{* * *}$ & & & & & \\
\hline spcsml & $-0.051^{*}$ & $0.241 * * *$ & -0.030 & 0.023 & -0.009 & $0.736^{* * *}$ & $0.974 * * *$ & & & & \\
\hline wcia & $-0.100 * * *$ & 0.017 & 0.012 & -0.038 & $0.635^{* * *}$ & $0.124 * * *$ & $0.050^{*}$ & $0.059 * *$ & & & \\
\hline tao & -0.046 & 0.018 & 0.042 & 0.042 & $0.165^{* * *}$ & $0.496 * * *$ & $0.446^{* * *}$ & $0.403^{* * *}$ & $0.221^{* * *}$ & & \\
\hline hfrx & $0.187^{* * *}$ & $-0.050^{*}$ & $-0.160 * * *$ & $-0.089 * * *$ & $-0.092 * * *$ & $0.309 * * *$ & $0.361^{* * *}$ & $0.342^{* * *}$ & $0.089 * * *$ & $0.486 * * *$ & \\
\hline usdeny & $-0.094 * * *$ & -0.019 & $0.058^{* *}$ & $0.071^{* *}$ & $-0.055^{* *}$ & $-0.157 * * *$ & $-0.213^{* * *}$ & $-0.202 * * *$ & $-0.075^{* * *}$ & $-0.403^{* * *}$ & $-0.283^{* * *}$ \\
\hline
\end{tabular}


Figure 2A U.S. Assets and Bitcoin Returns through Time

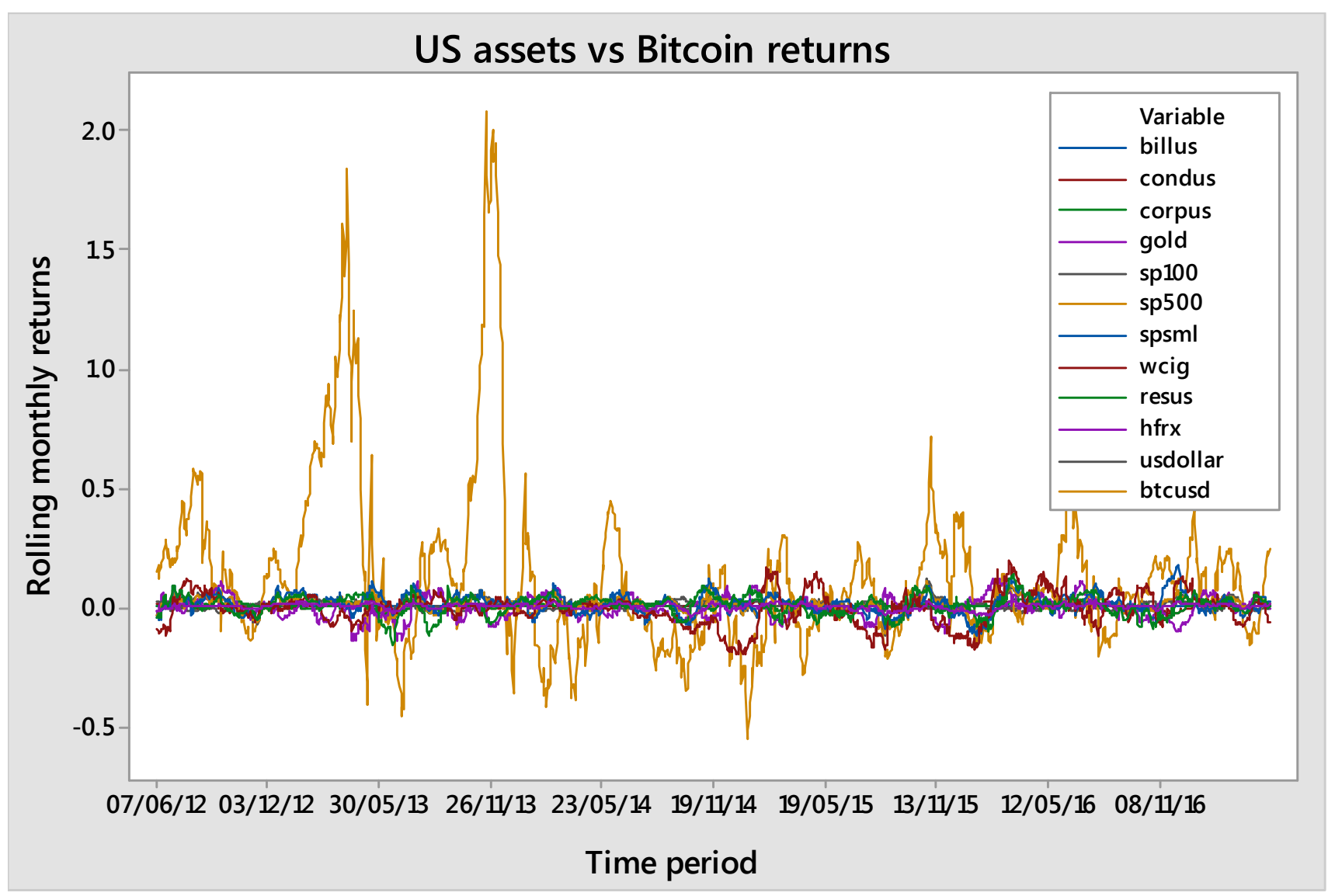


Figure 2B European Assets and Bitcoin returns through Time

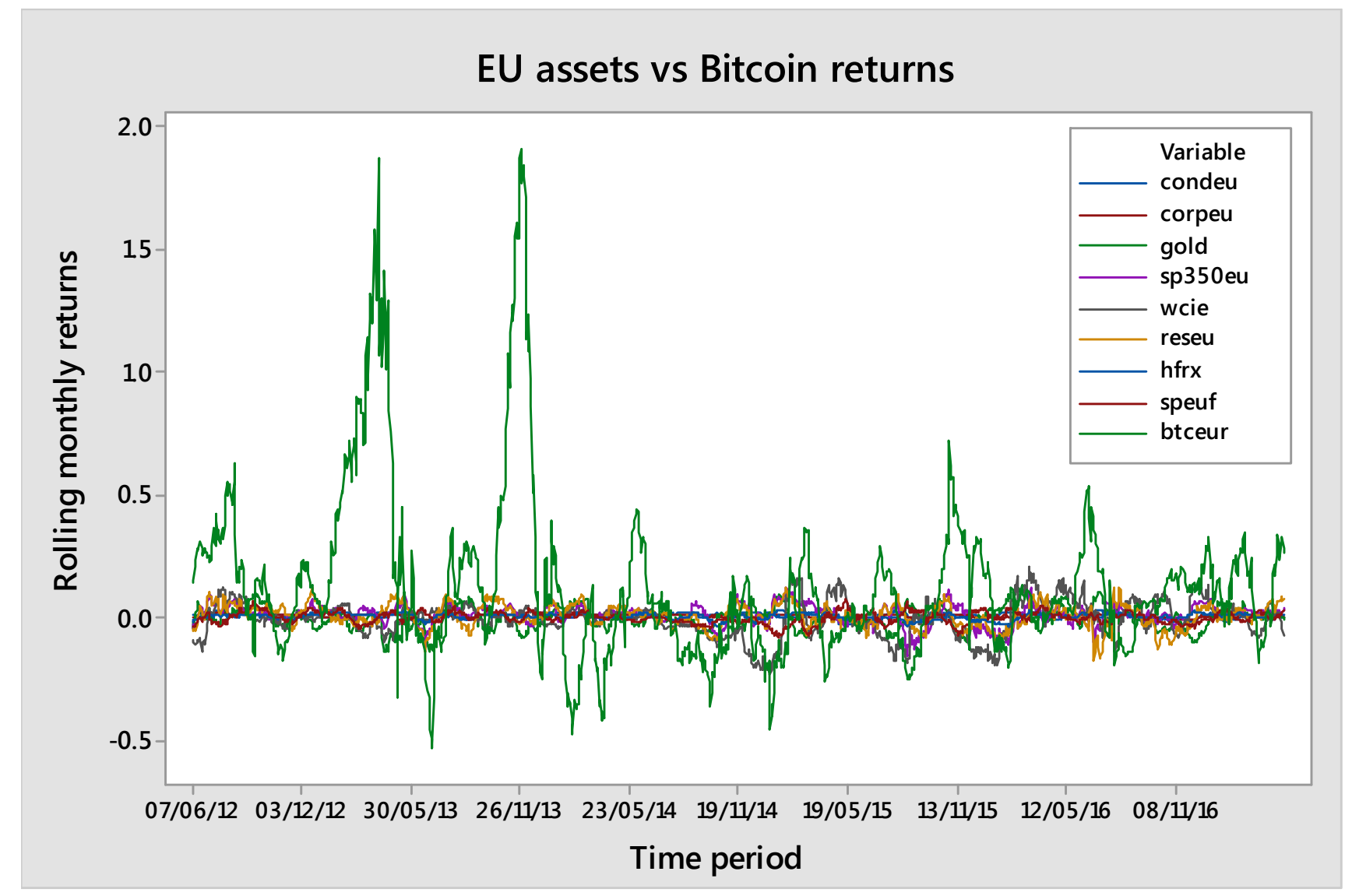


Figure 2C Chinese Assets and Bitcoin Returns through Time

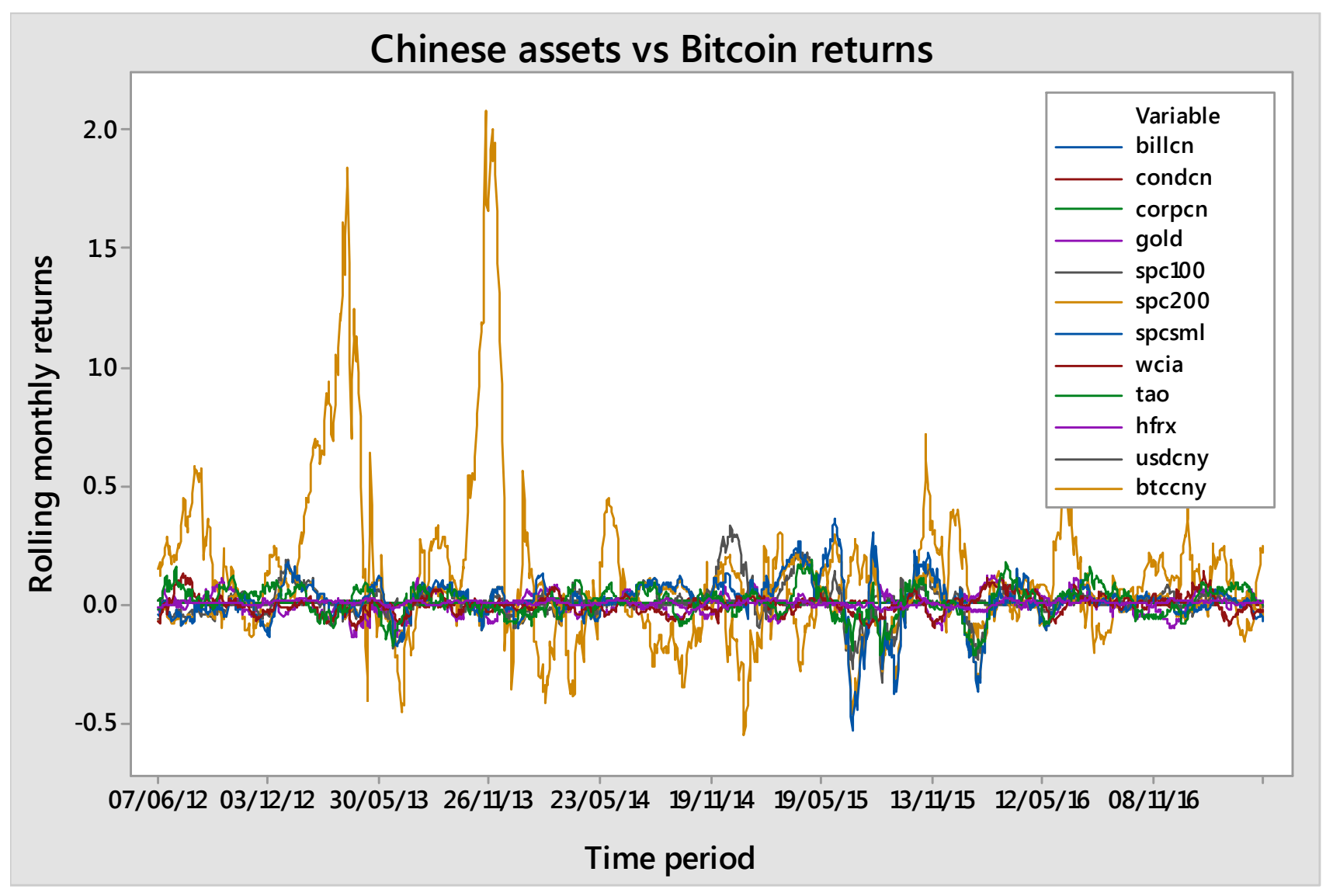


Table 4 Portfolio of U.S. Assets: Bitcoin Weights in Portfolio with Semi-Annual Rebalancing

Semi-annual BTC weights

\begin{tabular}{rrrr}
\multicolumn{1}{c}{ Portfolio } & Long-only & Semi-C. & btc>1 \\
\hline \hline Jun-13 & $14.24 \%$ & $1.30 \%$ & $1.30 \%$ \\
Dec-13 & $10.65 \%$ & $1.80 \%$ & $1.80 \%$ \\
Jun-14 & $13.84 \%$ & $3.70 \%$ & $3.70 \%$ \\
Dec-14 & $0.00 \%$ & $0.01 \%$ & $0.01 \%$ \\
Jun-15 & $0.00 \%$ & $0.74 \%$ & $0.74 \%$ \\
Dec-15 & $0.48 \%$ & $0.47 \%$ & $0.47 \%$ \\
Jun-16 & $4.43 \%$ & $6.85 \%$ & $6.85 \%$ \\
Dec-16 & $0.08 \%$ & $8.19 \%$ & $8.19 \%$ \\
\hline Bitcoin Mean & $5.47 \%$ & $2.88 \%$ & $2.88 \%$ \\
\hline \hline
\end{tabular}


Table 5A Portfolio of U.S. Assets: Performance - No Rebalancing

\begin{tabular}{|c|c|c|c|c|c|c|c|c|c|c|c|c|}
\hline & \multicolumn{3}{|c|}{ Naive } & \multicolumn{3}{|c|}{ long-only } & \multicolumn{3}{|c|}{ semi constrained } & \multicolumn{3}{|c|}{ constrained no $B T C<0$} \\
\hline & Base & BTC & Change & Base & BTC & Change & Base & BTC & Change & Base & BTC & Change \\
\hline Performance & $0.29 \%$ & $0.96 \%$ & $231.75 \%$ & $0.19 \%$ & $0.85 \%$ & $360.19 \%$ & $0.82 \%$ & $0.77 \%$ & $-6.67 \%$ & $0.82 \%$ & $0.77 \%$ & $-6.67 \%$ \\
\hline std dev & 0.0088 & 0.0196 & $122.57 \%$ & 0.0058 & 0.0291 & $405.07 \%$ & 0.0128 & 0.0103 & $-19.79 \%$ & 0.0128 & 0.0103 & $-19.79 \%$ \\
\hline Risk-Return (Cvar) & 0.0127 & 0.0176 & $38.58 \%$ & 0.0070 & 0.0155 & $121.43 \%$ & 0.9100 & 1.3500 & $48.35 \%$ & 0.9100 & 1.3500 & $48.35 \%$ \\
\hline Omega & 0.9517 & 2.4681 & $159.33 \%$ & 2.4220 & 3.4702 & $43.28 \%$ & 7.9503 & 10.7326 & $35.00 \%$ & 7.9503 & 10.7326 & $35.00 \%$ \\
\hline Sortino & 0.5112 & 1.7165 & $235.78 \%$ & 0.7752 & 1.0140 & $30.80 \%$ & 2.3513 & 2.4556 & $4.44 \%$ & 2.3513 & 2.4556 & $4.44 \%$ \\
\hline
\end{tabular}


Table 5B Portfolio of U.S. Assets: Performance - rebalancing

\begin{tabular}{|c|c|c|c|c|c|c|c|c|c|}
\hline & \multicolumn{3}{|c|}{ long-only } & \multicolumn{3}{|c|}{ semi constrained } & \multicolumn{3}{|c|}{ constrained no BTC $<0$} \\
\hline & Base & BTC & Change & Base & BTC & Change & Base & BTC & Change \\
\hline Performance & $0.19 \%$ & $0.85 \%$ & $360.19 \%$ & $0.58 \%$ & $0.57 \%$ & $-2.10 \%$ & $0.58 \%$ & $0.57 \%$ & $-2.10 \%$ \\
\hline std dev & 0.0058 & 0.0291 & $405.07 \%$ & 0.0086 & 0.0098 & $14.03 \%$ & 0.0086 & 0.0098 & $14.03 \%$ \\
\hline Risk-Return (Cvar) & 0.0133 & 0.0159 & $19.55 \%$ & 0.0940 & 0.0950 & $1.06 \%$ & 0.0940 & 0.0950 & $1.06 \%$ \\
\hline Omega & 1.8171 & 2.5787 & $41.91 \%$ & 3.0031 & 1.8159 & $-39.53 \%$ & 3.0031 & 1.8159 & $-39.53 \%$ \\
\hline Sortino & 0.6532 & 0.7541 & $15.46 \%$ & 4.0466 & 1.8454 & $-54.40 \%$ & 4.0466 & 1.8454 & $-54.40 \%$ \\
\hline
\end{tabular}


Table 6 Portfolio of European Assets: Bitcoin Weights in Portfolio with Semi-Annual Rebalancing

Semi-annual BTC weights

\begin{tabular}{rrrr}
\multicolumn{1}{l}{ Portfolio } & Long-only & \multicolumn{1}{c}{ Semi-C. } & \multicolumn{1}{l}{ btc>1 } \\
\hline Jun-13 & $35.46 \%$ & $11.52 \%$ & $11.52 \%$ \\
Dec-13 & $17.53 \%$ & $6.82 \%$ & $6.82 \%$ \\
Jun-14 & $16.25 \%$ & $1.39 \%$ & $1.39 \%$ \\
Dec-14 & $0.28 \%$ & $0.01 \%$ & $0.01 \%$ \\
Jun-15 & $0.00 \%$ & $-2.02 \%$ & $0.00 \%$ \\
Dec-15 & $55.05 \%$ & $-2.37 \%$ & $0.00 \%$ \\
Jun-16 & $26.15 \%$ & $1.26 \%$ & $1.26 \%$ \\
Dec-16 & $56.31 \%$ & $1.71 \%$ & $1.71 \%$ \\
\hline Bitcoin Mean & $25.88 \%$ & $2.29 \%$ & $2.84 \%$ \\
\hline
\end{tabular}


Table 7A Portfolio of European Assets: Performance - No Rebalancing

\begin{tabular}{|c|c|c|c|c|c|c|c|c|c|c|c|c|}
\hline & \multicolumn{3}{|c|}{ Naïve } & \multicolumn{3}{|c|}{ long-only } & \multicolumn{3}{|c|}{ semi constrained } & \multicolumn{3}{|c|}{ constrained no $B T C<0$} \\
\hline & Base & BTC & Change & Base & BTC & Change & Base & BTC & Change & Base & BTC & Change \\
\hline Performance & $-0.43 \%$ & $0.51 \%$ & $217.30 \%$ & $-0.01 \%$ & $2.56 \%$ & $19844.81 \%$ & $0.46 \%$ & $0.75 \%$ & $63.64 \%$ & $0.46 \%$ & $0.74 \%$ & $60.84 \%$ \\
\hline std dev & 0.0111 & 0.0246 & $121.32 \%$ & 0.0126 & 0.0695 & $450.74 \%$ & 0.0181 & 0.0236 & $30.91 \%$ & 0.0181 & 0.0236 & $30.91 \%$ \\
\hline Risk-Return (Cvar) & 0.0200 & 0.0300 & $50.00 \%$ & 0.0300 & 0.0500 & $66.67 \%$ & 0.0300 & 0.0200 & $-33.33 \%$ & 0.0300 & 0.0200 & $-33.33 \%$ \\
\hline Omega & 0.4920 & 1.7221 & $250.02 \%$ & 0.9749 & 3.6227 & $271.58 \%$ & 1.8818 & 2.7011 & $43.54 \%$ & 1.8818 & 2.7008 & $43.52 \%$ \\
\hline Sortino & -0.5225 & 0.5056 & $196.77 \%$ & -0.0166 & 1.4491 & $8828.22 \%$ & 0.5366 & 1.0070 & $87.66 \%$ & 0.5366 & 1.0068 & $87.63 \%$ \\
\hline
\end{tabular}


Table 7B Portfolio of European Assets: Performance - Rebalancing

\begin{tabular}{|c|c|c|c|c|c|c|c|c|c|}
\hline & \multicolumn{3}{|c|}{ long-only } & \multicolumn{3}{|c|}{ semi constrained } & \multicolumn{3}{|c|}{ constrained no $B T C<0$} \\
\hline & Base & BTC & Change & Base & BTC & Change & Base & BTC & Change \\
\hline Performance & $-0.52 \%$ & $2.44 \%$ & $569.28 \%$ & $0.46 \%$ & $0.76 \%$ & $62.95 \%$ & $0.46 \%$ & $0.82 \%$ & $76.93 \%$ \\
\hline std dev & 0.0176 & 0.0634 & $261.07 \%$ & 0.0086 & 0.0204 & $137.87 \%$ & 0.0086 & 0.0204 & $137.19 \%$ \\
\hline Risk-Return (Cvar) & 0.0400 & 0.0300 & $25.00 \%$ & 0.0100 & 0.0100 & $0.00 \%$ & 0.0100 & 0.0100 & $0.00 \%$ \\
\hline Omega & 0.4663 & 3.0728 & $558.95 \%$ & 1.7026 & 2.8050 & $64.75 \%$ & 1.7026 & 3.0075 & $76.64 \%$ \\
\hline Sortino & -0.4044 & 1.9553 & $583.55 \%$ & 1.1433 & 1.9624 & $71.64 \%$ & 1.1433 & 2.1541 & $88.42 \%$ \\
\hline
\end{tabular}


Table 8 Portfolio of Chinese Assets: Bitcoin Weights in Portfolio with Semi-Annual Rebalancing

Semi-annual BTC weights

Portfolio

Long-only Semi-C. BTC>0

Jun-13 $\quad 34.89 \% \quad 0.74 \% \quad 0.74 \%$

Dec-13 $\quad 9.31 \% \quad 0.79 \% \quad 0.79 \%$

Jun-14 $\quad 4.33 \% \quad 4.78 \% \quad 4.78 \%$

$\begin{array}{llll}\text { Dec-14 } & 0.31 \% & 0.44 \% & 0.44 \%\end{array}$

$\begin{array}{llll}\text { Jun-15 }-0.00 \% & 0.10 \% & 0.10 \%\end{array}$

$\begin{array}{llll}\text { Dec-15 } & 0.75 \% & -1.35 \% & 2.42 \%\end{array}$

Jun-16 $\quad 4.32 \% \quad-2.22 \% \quad 0.05 \%$

\begin{tabular}{llll} 
Dec-16 & $3.42 \%$ & $0.69 \%$ & $0.69 \%$ \\
\hline
\end{tabular}

\begin{tabular}{llll} 
Bitcoin Mean & $7.17 \%$ & $0.50 \%$ & $1.25 \%$ \\
\hline
\end{tabular} 
Table 9A Portfolio of Chinese Assets: No Rebalancing

\begin{tabular}{|c|c|c|c|c|c|c|c|c|c|c|c|c|}
\hline & \multicolumn{3}{|c|}{ Naïve } & \multicolumn{3}{|c|}{ long-only } & \multicolumn{3}{|c|}{ semi constrained } & \multicolumn{3}{|c|}{ constrained no BTC $<0$} \\
\hline & Base & BTC & Change & Base & BTC & Change & Base & BTC & Change & Base & BTC & Change \\
\hline Performance & $0.34 \%$ & $0.99 \%$ & $191.89 \%$ & $0.13 \%$ & $3.13 \%$ & $2226.01 \%$ & $0.16 \%$ & $0.14 \%$ & $-13.3 \%$ & $0.16 \%$ & $0.14 \%$ & $-13.3 \%$ \\
\hline std dev & 0.0166 & 0.0192 & $15.51 \%$ & 0.0038 & 0.0687 & $1705.03 \%$ & 0.0079 & 0.0069 & $-12.0 \%$ & 0.0079 & 0.0069 & $-12.0 \%$ \\
\hline Risk-Return (Cvar) & 0.0020 & 0.0020 & $0.00 \%$ & 0.0010 & 0.0050 & $400.00 \%$ & 0.0220 & 0.0300 & $36.4 \%$ & 0.0220 & 0.0300 & $36.4 \%$ \\
\hline Omega & 1.0667 & 1.4790 & $38.64 \%$ & 2.2797 & 4.2014 & $84.30 \%$ & 1.6518 & 1.6480 & $-0.2 \%$ & 1.6518 & 1.6480 & $-0.2 \%$ \\
\hline Sortino & 0.2711 & 0.8706 & $221.14 \%$ & 0.7593 & 1.9091 & $151.43 \%$ & 0.3792 & 0.4267 & $12.5 \%$ & 0.3792 & 0.4267 & $12.5 \%$ \\
\hline
\end{tabular}


Table 9B Portfolio of Chinese Assets: With Rebalancing

\begin{tabular}{|c|c|c|c|c|c|c|c|c|c|}
\hline & \multicolumn{3}{|c|}{ long-only } & \multicolumn{3}{|c|}{ semi constrained } & \multicolumn{3}{|c|}{ constrained no $B T C<0$} \\
\hline & Base & BTC & Change & Base & BTC & Change & Base & BTC & Change \\
\hline Performance & $0.12 \%$ & $1.96 \%$ & $1598.20 \%$ & $0.82 \%$ & $0.77 \%$ & $-6.67 \%$ & $0.82 \%$ & $0.85 \%$ & $3.69 \%$ \\
\hline std dev & 0.0169 & 0.0587 & $248.15 \%$ & 0.0128 & 0.0121 & $-5.51 \%$ & 0.0128 & 0.0121 & $-5.51 \%$ \\
\hline Risk-Return (Cvar) & 0.0020 & 0.0020 & $0.00 \%$ & 0.0029 & 0.0037 & $27.59 \%$ & 0.0010 & 0.0010 & $0.00 \%$ \\
\hline Omega & 0.7494 & 2.3893 & $218.83 \%$ & 2.2574 & 2.3038 & $2.06 \%$ & 2.2574 & 1.5766 & $-30.16 \%$ \\
\hline Sortino & 0.0573 & 0.9282 & $1521.06 \%$ & 1.4306 & 1.2292 & $-14.08 \%$ & 1.4306 & 1.2239 & $-14.44 \%$ \\
\hline
\end{tabular}

